Document downloaded from:

http://hdl.handle.net/10251/46109

This paper must be cited as:

Miguel Sosa, P.; Juan Navarro-Gregori; Fernández Prada, MA.; Bonet Senach, JL. (2013). A simplified method to predict the ultimate shear stress of reinforcedconcrete membrane elements. Engineering Structures. 49:329-344. doi:10.1016/j.engstruct.2012.11.009.

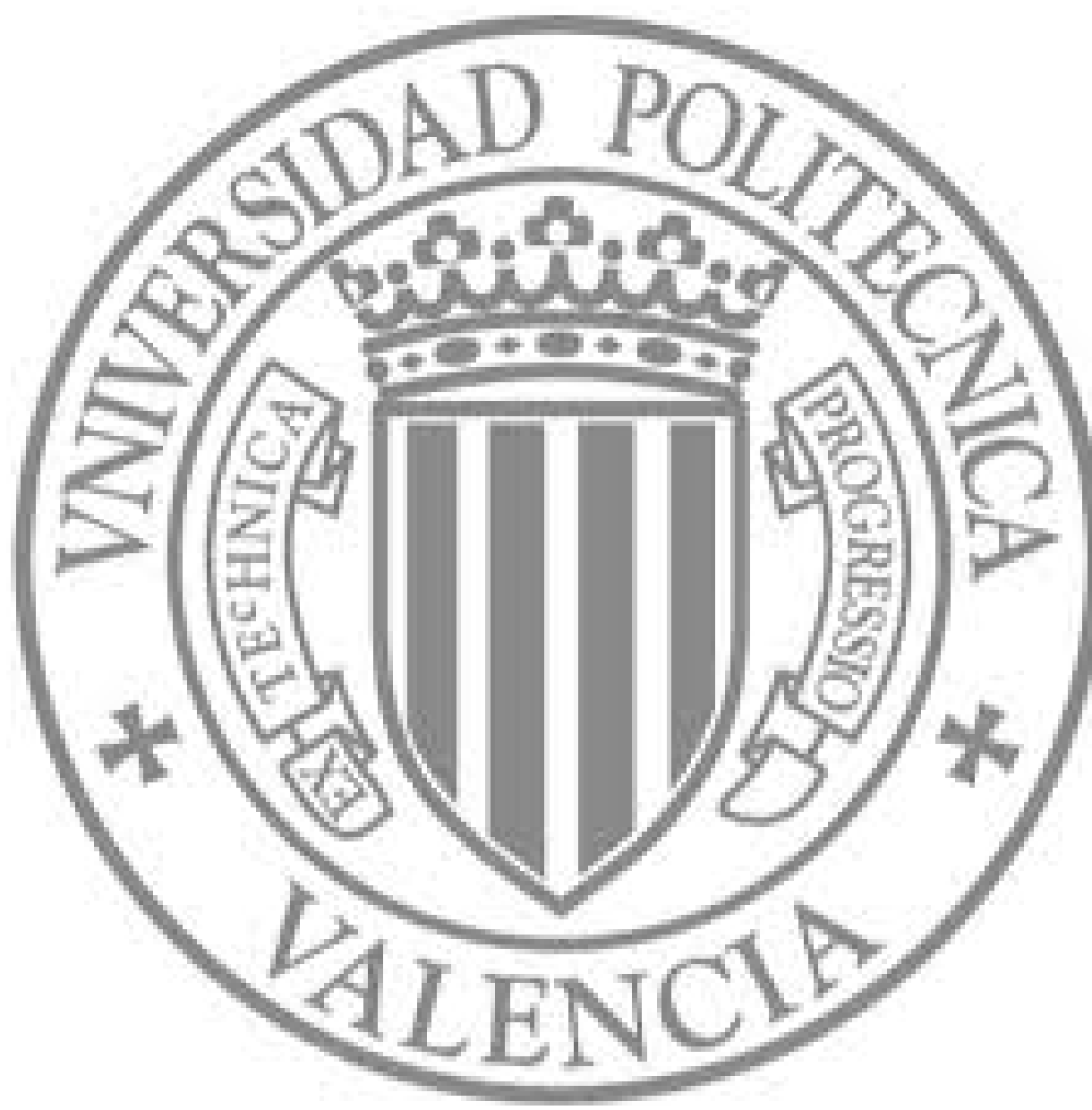

The final publication is available at

http://dx.doi.org/10.1016/j.engstruct.2012.11.009

Copyright Elsevier 


\title{
A SIMPLIFIED METHOD TO PREDICT THE ULTIMATE SHEAR STRESS OF REINFORCED CONCRETE MEMBRANE ELEMENTS
}

Pedro F. Miguel a, ${ }^{\text {* }}$, Juan Navarro-Gregori ${ }^{\mathrm{a}}$, Miguel. A. Fernández-Prada ${ }^{\mathrm{a}}$, José L. Bonet ${ }^{\mathrm{a}}$

a Instituto de Ciencia y Tecnología del Hormigón (ICITECH), Departamento de Ingeniería de la Construcción y de Proyectos de Ingeniería Civil, Universitat Politècnica de Valencia, Camino de Vera s/n, 46022, Valencia, Spain.

*Tel.: +34 963877007 ext. 75611 ; fax +3496387 7569 .

Email address: pmiguel@,cst.upv.es

\begin{abstract}
This paper presents a new simplified verification method to predict the ultimate shear stress and the mode of failure of reinforced concrete membrane elements with orthogonal reinforcement under any combination of normal stresses. This method is based on a simplified model designed to take the condition of the concrete at failure into account. The methodology is non-iterative, simple and easy to use for practical purposes. The accuracy of the verification method has been checked using test results from $88 \mathrm{RC}$ membrane elements subjected to a wide range of in-plane normal and shear stresses, concrete strengths, and reinforcement ratios for both $\mathrm{x}$ and $\mathrm{y}$ directions. Moreover, the proposed method is compared with MCFT using Membrane-2000 software and other simplified methods (SMCS by Rahal 2010, the Marti-Kauffman method 1998 and the Mancini proposal 2001). The proposed method strikes a balance between a general view, accuracy and simplicity, using a wide range of tests that cover different modes of failure.
\end{abstract}

Keywords: membrane element, reinforced concrete, compression, tension, shear, strength, failure Highlights: $>\mathrm{A}$ verification method to predict the ultimate shear stress of $\mathrm{RC}$ membrane elements is presented $>$ the method predicts the mode of failure under any combination of normal stresses $>$ the verification method does not require an iterative process and its application is straightforward $>$ the method provides good agreement with 88 experimental tests that cover different modes of failure $>$ the method provides greater accuracy in comparison with other simplified methods 


\section{Introduction}

Designers frequently model reinforced concrete structures as assembled membrane elements subjected to in-plane normal and shear stresses. Over the last three decades, multiple efforts have been made to provide theories and models to predict the load-deformation behavior and the ultimate shear stress of these elements. The complexity of the mechanical behavior of $\mathrm{RC}$ membrane elements hinders the formulation of models combining the three main aspects needed for practical purposes: a general view, accuracy and simplicity.

The following models have been considered major contributions to this aim: Vecchio and Collins (1986) [18], Hsu [8],[9],[10], Kaufmann and Marti (1998) [11], Vecchio (2000) [19] and (2001) [20], Carbone, Giordano and Mancini (2001) [4], Bentz, Vecchio and Collins (2006) [2], and Rahal (2008) [16] and (2010) [15]. The main features on which these models are based are summarized below. In the Modified Compression Field Theory (MCFT) proposed by Vecchio and Collins (1986) [18], equilibrium, compatibility and constitutive equations are formulated in terms of average stresses and strains, considering the effect of cracks distributed over a portion of the element. This is a rotating crack model that provides accurate results compared with experimental tests, but leads to a complex set of equations that can only be solved using an iterative process. An improvement of MCFT, called DSFM, was later proposed by Vecchio (2000) [19] and (2001) [20] to provide improved simulations or responses in situations where MCFT was found to produce inaccuracies, such as in the case of panels containing heavy reinforcement, panels reinforced mainly in one direction, or in shear-critical beams with little or no transverse reinforcement. In this model a better behavior of concrete is introduced, using a formulation which is a hybrid between a fully rotating crack formulation and a fixed crack model and which explicitly allows for crack shear slip in the description of element formulation. The DSFM material model is also based on a relatively complex formulation that requires an iterative process. Hsu's models [8]-[9]-[10] are also based on equilibrium, compatibility and constitutive laws with softened concrete, assuming rotating or fixed crack angles. Again, the set of equations has to be solved using an iterative process. All the models described in this paragraph are difficult to apply and are more geared towards implementation in 2D FEM models, or section analysis with coupling between normal and shear stresses.

The Cracked Membrane Model proposed by Kaufmann and Marti (1998) [11] combines the basic concepts of the tension chord model and MCFT. Equilibrium equations are formulated in terms of stresses at the cracks rather than average stresses between the cracks, even though the treatment of 
tension-stiffening is different from that of MCFT. An iterative process is also needed to find the strains from the given stresses in the Cracked Membrane Model. Nevertheless, the simplifications established for limit analysis formulation lead to an approximate analytical solution that makes it easy to design and check RC membrane elements. The predicted ultimate shear stress values in this model are good when the failure mode is governed by reinforcement yielding and less accurate when reinforcement does not yield in any direction.

The Carbone, Giordano and Mancini (2001) [4] model is based on the assumption that concrete compression strength is a function of the difference between two angles: the inclination of the diagonal stresses at ultimate limit state $\theta_{\mathrm{p}}$ and the angle of the principal compressive stresses in uncracked state $\theta_{\mathrm{e}}$, just before cracking. The basic elements of this proposal have been adopted by Eurocode 2-2 [6] for membrane elements. This method provides a set of inequalities that makes it easy to identify a range of values of ultimate shear stress as a function of the inclination of stresses in concrete, assuming perfectly plastic behavior. It gives acceptable accuracy, but requires an iterative process to find the $\theta_{\mathrm{p}}$ angle which provides the maximum ultimate shear stress.

A simplified version of the DSFM model, useful in predicting the shear strength of beams, was presented by Bentz, Vecchio and Collins (2006) [2]. This model has been included in several codes such as CSA A23.3-04 [5], AASHTO LFRD [1]. The application of this model to membrane elements is limited since it does not account for biaxial normal stresses and is meant to be used for the prediction of the shear strength of reinforced concrete beams.

Rahal (2000) [14] proposed an alternative simplified model based on MFCT to predict the strength and the mode of failure of membrane elements. In Rahal (2008) [16], the same author proposed another modified non-iterative model called SMCS, a straightforward procedure based on very simple equations for the strength values and failure modes. Moreover, Rahal 2010 [15] presents a validation of the SMCS model for the shear-transfer problem. However, Rahal's model only distinguishes between the modes of failure in which steel yields under tension in any direction.

The aim of this paper is to present a new simplified model to take into account the failure behavior of membrane elements with orthogonal reinforcement. The model considers the softening effect of concrete compressive strength due to transverse tensile strains.

Based on this new simplified model a verification method is proposed for predicting the ultimate shear stress and the mode of failure of RC membrane elements subjected to any given combination of normal 
stresses. Regarding the mode of failure, the method aims to offer a straightforward prediction of the steel stresses in both reinforcements. It distinguishes whether the reinforcement yields or not, and also whether the steel is in tension or in compression. Thus, the method proposed is more general than other simplified methods, such as those of Kaufmann and Marti (1998) [11], Carbone, Giordano and Mancini (2001) [4], or Rahal (2008) [16], as it covers the whole range of combinations of normal stresses in compression and tension.

\section{Model formulation}

The formulation of a simplified model to consider the behavior of concrete at ultimate is presented in this section. This proposal will serve as the basis for developing the verification method presented in section 3. It is worth noting that the model is formulated in terms of average strains and stresses.

\subsection{Equilibrium equations}

Equilibrium equations of a concrete membrane element, reinforced orthogonally and aligned with the reference axis, may be established by assuming that reinforcement bars can only withstand axial stresses

(Fig.1). Hence, the superposition principle for concrete and steel may be applied as follows:

$$
\begin{aligned}
& \sigma_{x}=\sigma_{c x}+\rho_{x} \cdot \sigma_{s x} \\
& \sigma_{y}=\sigma_{c y}+\rho_{y} \cdot \sigma_{s y} \\
& \tau_{x y}=\tau_{c x y}
\end{aligned}
$$

From the Mohr stress circle (Fig.1), the angle of inclination of the principal stress $\left(\theta_{\sigma}\right)$ axis can be expressed by:

$$
\operatorname{tg} \theta_{\sigma}=\frac{\tau_{c x y}}{\sigma_{c 1}-\sigma_{c x}}=\frac{\sigma_{c 1}-\sigma_{c y}}{\tau_{c x y}}=\frac{\tau_{c x y}}{\sigma_{c y}-\sigma_{c 2}}=\frac{\sigma_{c x}-\sigma_{c 2}}{\tau_{c x y}}
$$

\subsection{Compatibility equations}

Assuming that the reinforcement has the same deformation as the surrounding concrete, the average strain values in $x$ and $y$ directions are equal for both materials. Hence:

$$
\begin{aligned}
& \varepsilon_{x}=\varepsilon_{c x}=\varepsilon_{s x} \\
& \varepsilon_{y}=\varepsilon_{c y}=\varepsilon_{s y}
\end{aligned}
$$

From the Mohr stress circle (Fig.1), the angle of inclination of the principal strain axis $\left(\theta_{\varepsilon}\right)$ can be expressed by: 


$$
\operatorname{tg}^{2} \theta_{\varepsilon}=\frac{\varepsilon_{s x}-\varepsilon_{2}}{\varepsilon_{1}-\varepsilon_{s x}}=\frac{\varepsilon_{1}-\varepsilon_{s y}}{\varepsilon_{s y}-\varepsilon_{2}}=\frac{\varepsilon_{s x}-\varepsilon_{2}}{\varepsilon_{s y}-\varepsilon_{2}}=\frac{\varepsilon_{1}-\varepsilon_{s y}}{\varepsilon_{1}-\varepsilon_{s x}}
$$

\subsection{Simplified assumptions}

Even though local steel strains in the crack are higher than average steel strains, the proposed model has only been formulated in terms of average strains and stresses.

Moreover, the model is considered to be a rotating-angle approach that assumes coaxiality. Thus, the angle of inclination of the principal strain axis $\left(\theta_{\varepsilon}\right)$ is the same as the angle of inclination of the principal stress axis $\left(\theta_{\sigma}\right)$.

Second, average tensile concrete stress is assumed to be $\sigma_{\mathrm{cl}}=0$. Thus, Eq. (2) and (4) give:

$$
\tan ^{2} \theta=\tan ^{2} \theta_{\sigma}=\frac{\tau_{x y}^{2}}{\sigma_{c x}^{2}}=\frac{\sigma_{c y}}{\sigma_{c x}}=\tan ^{2} \theta_{\varepsilon}=\frac{\varepsilon_{s x}-\varepsilon_{2}}{\varepsilon_{1}-\varepsilon_{s x}}=\frac{\varepsilon_{1}-\varepsilon_{s y}}{\varepsilon_{s y}-\varepsilon_{2}}
$$

Following these simplified assumptions, it is possible to express the principal strain $\left(\varepsilon_{1}\right)$ as a function of only one of the average steel strains ( $\varepsilon_{\mathrm{sx}}$ or $\left.\varepsilon_{\mathrm{sy}}\right)$, the principal strain $\left(\varepsilon_{2}\right)$, and the average concrete normal stresses $\left(\sigma_{\mathrm{cx}}, \sigma_{\mathrm{cy}}\right)$ as follows:

$$
\begin{aligned}
& \varepsilon_{1}=\varepsilon_{s x}+\frac{\sigma_{c x}}{\sigma_{c y}}\left(\varepsilon_{s x}-\varepsilon_{2}\right) \\
& \varepsilon_{1}=\varepsilon_{s y}+\frac{\sigma_{c y}}{\sigma_{c x}}\left(\varepsilon_{s y}-\varepsilon_{2}\right)
\end{aligned}
$$

It is important to note that the principal strain $\left(\varepsilon_{1}\right)$ does not depend on the shear stress applied to the membrane element $\left(\tau_{\mathrm{xy}}\right)$.

Finally, the assumption of $\sigma_{c 1}=0$ leads to an equilibrium equation directly derived from Eq. (2), that must apply the average concrete stresses $\sigma_{c x}$ and $\sigma_{c y}$ for a given shear stress $\tau_{x y}$. Hence:

$$
\sigma_{c x} \cdot \sigma_{c y}=\tau_{x y}^{2}
$$

\subsection{Failure conditions for concrete}

With the state of stresses applied to concrete $\left(\sigma_{c x}, \sigma_{c y}\right.$ and $\left.\tau_{c x y}\right)$, two modes of failure can occur: (a) crushing of concrete struts with diagonal cracking or (b) crushing of concrete in a state of biaxial compressive stresses. Any other modes of failure that may occur in a reinforced concrete membrane element are out of the scope of the proposed simplified model, such as the so-called crack slip mechanism in elements with very low or no reinforcement, and the failure of the reinforcing bars in elements with 
low reinforcement ratios and/or steel with low ductility. The failure conditions of the two modes of failure considered can be expressed as follows.

\section{(a) Crushing of concrete struts with diagonal cracking}

In this failure mode, the compressive concrete strength is reduced due to the existing tensile strain normal to the strut direction. Thus:

$$
\sigma_{c 2}=\sigma_{c x}+\sigma_{c y} \geq-\xi \cdot f_{c}
$$

where $\xi \leq 1$ is a softening factor that can be formulated as a function of the principal tensile strain $\varepsilon_{1}$. Vecchio and Collins (1986) [18] proposed the following coefficient to take the softening effect into account:

$$
\xi=\frac{1}{0.8+0.34 \cdot \varepsilon_{1} / \varepsilon_{c 0}} \leq 1
$$

where $\varepsilon_{\mathrm{c} 0}$ is the strain at peak stress of the stress-strain curve for concrete.

In this mode of failure, it is reasonable to consider that the principal compressive strain of concrete $\left(\varepsilon_{2}\right)$ at failure is equal to the strain at concrete peak stress $\left(-\varepsilon_{\mathrm{c} 0}\right)$.

The simplified assumptions stated in section 2.3 can be included in the failure condition just by substituting Eq. (6) into (9), and then incorporating the resulting expression into (8). Thus, the failure condition may be formulated as a function of the two concrete normal stresses at failure $\left(\sigma_{\mathrm{cxu}}, \sigma_{\mathrm{cyu}}\right)$, and only one of the two average steel strains $\left(\varepsilon_{\mathrm{sx}}\right.$ or $\left.\varepsilon_{\mathrm{sy}}\right)$. Moreover, since the principal strains do not depend on the shear stress applied to the membrane element $\left(\tau_{\mathrm{xy}}\right)$, the derived failure condition does not depend on the shear stress applied.

Fig. 2 shows curves $(c 1)$ and $(c 2)$ corresponding to this failure condition when the average strains in the reinforcement in $\mathrm{x}$ and y direction are expressed as $\varepsilon_{\mathrm{sx}}=\varepsilon_{\mathrm{yx}}$ and $\varepsilon_{\mathrm{sy}}=\varepsilon_{\mathrm{yy}}$ respectively, where $\varepsilon_{\mathrm{yx}}=f_{y x} / E_{s}$, $\varepsilon_{\mathrm{yy}}=f_{y y} / E_{s}$ is the steel yield strain in both directions. These two curves ( $c 1$ and $\left.c 2\right)$ do not depend on the value of the shear stress $\tau_{x y}$ applied to the membrane element. Furthermore, curve $(c 1)$ has a minimum of $\sigma_{c x u}$ and curve (c2) has a minimum of $\sigma_{c y u}$.

Fig. 2 also shows curves $(d 1)$ and $(d 2)$ corresponding to the failure condition of concrete for $\varepsilon_{s x}=0$ and $\varepsilon_{s y}=0$, respectively. These curves have a similar shape to that of curves $(c 1)$ and $(c 2)$, and it can be seen that they are virtually homothetic in directions $x$ and $y$, respectively. 
Moreover, the equilibrium equation derived in (7) can be expressed at failure conditions (curve $(a)$ in Fig.

2) as follows:

$\sigma_{c x u} \cdot \sigma_{c y u}=\tau_{x y}^{2}$

Thus, intersection points $(A$ and $F$ ) between curves $(a)$ and $(c l)$ represent concrete stresses at failure when the strain $\varepsilon_{s x}$ is equal to $\varepsilon_{y x}$. In the same way, intersection points ( $B$ and $E$ ) between curves $(a)$ and $(c 2)$ represent concrete stresses at failure when the strain $\varepsilon_{s y}$ is equal to $\varepsilon_{y y}$. It is important to highlight that every point of curve $(a)$ represents concrete stresses at failure for different levels of strains in the reinforcement. For example, points of curve $(a)$ between $A$ and $B$ represent the failure of concrete with strains in both directions of reinforcement higher than or equal to $\varepsilon_{y x}$ and $\varepsilon_{y y}$, that is, both reinforcements yield in tension before concrete crushing. Points between $A$ and $C$ represent the failure of concrete with 0 $\leq \varepsilon_{s x}<\varepsilon_{y x}$ and $\varepsilon_{s y}>\varepsilon_{y y}$ (only $-y$ reinforcement yields in tension before concrete crushing), while points between $B$ and $D$ represent the failure of concrete with $0 \leq \varepsilon_{s y}<\varepsilon_{y y}$ and $\varepsilon_{s x}>\varepsilon_{y y}$ (only $-x$ reinforcement yields in tension before concrete crushing). Fig.2 shows the strains of both reinforcements for every interval of curve (a).

\section{b) Crushing of concrete under biaxial compressive stresses}

If concrete is not cracked at failure, a simple way of considering the failure condition is to limit compressive principal stress $\sigma_{c 2} \geq-f_{c}$. From Eq. (2) this failure condition can be expressed as follows:

$$
\left(\sigma_{c x u}+f_{c}\right) \cdot\left(\sigma_{c y u}+f_{c}\right) \geq \tau_{x y}^{2} \text { with } \sigma_{c x u}+\sigma_{c y u}<-f_{c}
$$

Curve $(b)$ in Fig. 2 represents the boundary line of this failure condition in the plane $\sigma_{c x}-\sigma_{c y}$.

As in the case of curve $(a)$, points of curve $(b)$ are associated with different strains of the reinforcement in both directions. The strains corresponding to a given point on this curve can be obtained from the ultimate concrete stresses $\sigma_{c x u}$ and $\sigma_{c y u}$ by assuming that concrete crushing is reached when $\sigma_{c 2}=-f_{c}$ and $\varepsilon_{c 2}=-\varepsilon_{c 0}$. Hence according to (4) and (5):

$$
\tan ^{2} \theta=\frac{\varepsilon_{s x}+\varepsilon_{c 0}}{\varepsilon_{s y}+\varepsilon_{c 0}}=\frac{\sigma_{c x u}+f_{c}}{\sigma_{c y u}+f_{c}}
$$

If the Poisson effect is neglected, it can be assumed that $\sigma_{c x}=E_{c, s e c} \cdot \varepsilon_{c x}$ and $\sigma_{c y}=E_{c, s e c} \cdot \varepsilon_{c y}$, where: 
$E_{c, \mathrm{sec}}=\frac{f_{c}}{\varepsilon_{c 0}}$

Moreover, given the fact that $\varepsilon_{c x}=\varepsilon_{s x}$ and $\varepsilon_{c y}=\varepsilon_{s y}$, the reinforcement steel strains along curve (b) can be obtained by:

$\varepsilon_{s x}=\frac{\sigma_{c x u}}{f_{c}} \cdot \varepsilon_{c 0}$
$\varepsilon_{s y}=\frac{\sigma_{c y u}}{f_{c}} \cdot \varepsilon_{c 0}$

\subsection{Proposed simplified model for failure condition of concrete}

Each of the curves (c1) and (c2) in Fig.2 are simplified by two straight lines $\left(c 1^{\prime}\right)$ and (c2) (Fig. 3), which can be expressed as follows:

$$
\begin{array}{cc}
\sigma_{c x, b a l, y}=-\beta_{y} \cdot \sigma_{c x, b a l} & \text { with } \beta_{y}=\frac{f_{c}+\sigma_{c y}}{f_{c}-\sigma_{c y, 0}} \leq 1 \\
\sigma_{c y, b a l, x}=-\beta_{x} \cdot \sigma_{c y, b a l} & \text { with } \beta_{x}=\frac{f_{c}+\sigma_{c x}}{f_{c}-\sigma_{c x, 0}} \leq 1
\end{array}
$$

Curves $(d 1)$ and $(d 2)$ are also simplified by $\left(d 1^{\prime}\right)$ and $(d 2)$, homothetic to $\left(c 1^{\prime}\right)$ and $(c 2)$, with a factor of 1.6 .

$$
\begin{aligned}
\sigma_{c x, 0, y} & =1.6 \cdot \sigma_{c x, b a l, y} \\
\sigma_{c y, 0, x} & =1.6 \cdot \sigma_{c y, b a l, x}
\end{aligned}
$$

These four simplified lines all depend on $\sigma_{\mathrm{cx} \text {,bal }}$ and $\sigma_{\mathrm{cy}, \text { bal }}$, which can be formulated as a function of the concrete compressive strength $f_{c}$, the peak strain of concrete $\varepsilon_{c 0}$, and the steel yield stress $f_{y x}$ or $f_{y y}$. The following simplified expressions are proposed:

$$
\begin{aligned}
& \sigma_{c x, b a l}=\left(0.33-33 \cdot \varepsilon_{c 0}\right) \cdot\left(\frac{500}{f_{y x}}\right)^{0.3} \cdot f_{c}=\alpha_{x} \cdot f_{c} ; \sigma_{c x, 0}=1.6 \cdot \alpha_{x} \cdot f_{c} \\
& \sigma_{c y, b a l}=\left(0.33-33 \cdot \varepsilon_{c 0}\right) \cdot\left(\frac{500}{f_{y y}}\right)^{0.3} \cdot f_{c}=\alpha_{y} \cdot f_{c} ; \sigma_{c y, 0}=1.6 \cdot \alpha_{y} \cdot f_{c}
\end{aligned}
$$

Finally, these simplified lines can be formulated as follows:

(c1') $\sigma_{c x}=-\alpha_{x} \beta_{y} f_{c} ;\left(\mathrm{d} 1^{\prime}\right) \sigma_{c x}=-1.6 \alpha_{x} \beta_{y} f_{c} ;\left(\mathrm{c} 2^{\prime}\right) \sigma_{c y}=-\alpha_{y} \beta_{x} f_{c} ;\left(\mathrm{d} 2^{\prime}\right) \sigma_{c y}=-1.6 \alpha_{y} \beta_{x} f_{c}$

Simplified lines (c1), (c2), (d1), and (d2) split the plane $\sigma_{c x}-\sigma_{c y}$ into several regions as shown in Fig. 3. 
It is interesting to note that $(c 1)$ and $(d 1)$ intersect the $\sigma_{c y}$ axis at $\left(-\mathrm{f}_{\mathrm{c}}\right)$, while $(c 2)$ and $(d 2)$ intersect the $\sigma_{c x}$ axis at $\left(-\mathrm{f}_{\mathrm{c}}\right)$.

It is assumed that the mode of failure in regions $A$ to $F$ (i.e. $\sigma_{c x}+\sigma_{c y}>-f_{c}$ ) is due to concrete crushing with diagonal cracking while in region $\mathrm{G}$ (i.e. $\sigma_{\mathrm{cx}}+\sigma_{\mathrm{cy}}<-\mathrm{f}_{\mathrm{c}}$ ) is due to concrete crushing with biaxial compression. Next, the methodology to evaluate steel stresses in each region and mode of failure is detailed given the ultimate concrete stresses $\sigma_{c x u}$ and $\sigma_{c y u}$.

For the case of biaxial compression (region G in Fig. 3), steel stresses can be obtained from (14) as follows:

$$
\begin{aligned}
& \sigma_{s x}^{b c}=E_{s x} \cdot \varepsilon_{s x}=E_{s x} \cdot \frac{\sigma_{c x u}}{f_{c}} \varepsilon_{c 0}=n_{x} \cdot \sigma_{c x u} \geq-f_{y x c} \\
& \sigma_{s y}^{b c}=E_{s y} \cdot \varepsilon_{s y}=E_{s y} \cdot \frac{\sigma_{c y u}}{f_{c}} \varepsilon_{c 0}=n_{y} \cdot \sigma_{c y u} \geq-f_{y y c}
\end{aligned}
$$

where $n_{i}=\mathrm{E}_{\mathrm{si}} \cdot \varepsilon_{\mathrm{c} 0} / \mathrm{f}_{\mathrm{c}}$ and $\mathrm{f}_{\mathrm{yic}}=E_{s} \cdot \varepsilon_{\mathrm{c} 0} \leq f_{y i}, i=$ ' $x$ ' or ' $y$ '

For the case of diagonal cracking (regions A to F in Fig.3), the method for obtaining the steel stresses in each region is different, and can be performed as set out below.

1. If $-\alpha_{x} \beta_{y} f_{c}<\sigma_{c x u}$ (regions $\mathrm{A}, \mathrm{B}^{\prime}$ and $\mathrm{D}^{\prime}$ ), the reinforcement in $x$ direction is assumed to yield in tension. Hence:

$$
\sigma_{s x 1}^{d c}=f_{y x}
$$

2. If $-1.6 \alpha_{x} \beta_{y} f_{c}<\sigma_{c x u} \leq-\alpha_{x} \beta_{y} f_{c}$ (regions $\mathrm{B}, \mathrm{C}$ and $\mathrm{E}^{\prime}$ ), the reinforcement in $x$ direction is in tension but does not yield. The stress of this reinforcement can be linearly interpolated between 0 and $f_{y x}$ for values of $\sigma_{c x}$ between $-1.6 \alpha_{x} \beta_{y} f_{c}$ and $-\alpha_{x} \beta_{y} f_{c}$. Hence:

$$
\sigma_{s x 2}^{d c}=\frac{\sigma_{c x u}+1.6 \alpha_{x} \beta_{y} f_{c}}{0.6 \alpha_{x} \beta_{y} f_{c}} f_{y x}
$$

3. If $\sigma_{c x u} \leq-1.6 \alpha_{x} \beta_{y} f_{c}$ (regions $\mathrm{D}, \mathrm{E}$ and $\mathrm{F}$ ), reinforcement in $x$ direction has a compressive stress between zero and $\sigma_{s x, \text { diag }}^{b c}$, which is the steel stress of the x-reinforcement just in the point of the diagonal that separates both modes of failure (i.e. $\sigma_{\mathrm{cx} \text {,diag }}=-\sigma_{\mathrm{cy}}-\mathrm{f}_{\mathrm{c}}$ ), and evaluated on the biaxial compression side according to (19). The stress of this reinforcement can be linearly 
interpolated between zero and $\sigma_{s x, \text { diag }}^{b c}$ for values of $\sigma_{\mathrm{cx}}$ between $-1.6 \alpha_{\mathrm{x}} \beta_{\mathrm{y}} f_{\mathrm{c}}$ and $\sigma_{\mathrm{cx}, \mathrm{diag}}=-\sigma_{\mathrm{cyu}}-f_{c}$ as follows:

$$
\sigma_{s x 3}^{d c}=\frac{\sigma_{c x u}+1.6 \alpha_{x} \beta_{y} f_{c}}{-\sigma_{c y u}-f_{c}+1.6 \alpha_{x} \beta_{y} f_{c}} \sigma_{s x, \text { diag }}^{b c} \rightarrow \sigma_{s x, d i a g}^{b c}=-n_{x} \cdot\left(\sigma_{c y u}+f_{c}\right) \geq-f_{y x c}
$$

Thus, steel stresses will be coincident for biaxial compression and diagonal cracking in the border line that separates both modes of failure.

Likewise, steel stress $\sigma_{s y}$ can be formulated as:

$$
\begin{aligned}
& \text { when }-\alpha_{y} \beta_{x} f_{c}<\sigma_{c y}(\mathrm{~A}, \mathrm{~B}, \text { and } \mathrm{D}) \rightarrow \sigma_{s y 1}^{d c}=f_{y y} \\
& \text { when }-1.6 \alpha_{y} \beta_{x} f_{c}<\sigma_{c y} \leq-\alpha_{y} \beta_{x} f_{c}\left(\mathrm{~B}^{\prime}, \mathrm{C} \text { and } \mathrm{E}\right) \rightarrow \sigma_{s y 2}^{d c}=\frac{\sigma_{c y}+1.6 \alpha_{y} \beta_{x} f_{c}}{0.6 \alpha_{y} \beta_{x} f_{c}} f_{y y}
\end{aligned}
$$

when $\sigma_{c y} \leq-1.6 \alpha_{x} \beta_{y} f_{c}\left(\mathrm{D}^{\prime}, \mathrm{E}^{\prime}\right.$, and $\left.\mathrm{F}\right)$

$$
\sigma_{s y 3}^{d c}=\frac{\sigma_{c y}+1.6 \alpha_{y} \beta_{x} f_{c}}{-\sigma_{c x}-f_{c}+1.6 \alpha_{y} \beta_{x} f_{c}} \sigma_{s y, \text { diag }}^{b c} \rightarrow \sigma_{s y, d i a g}^{b c}=-n_{y}\left(\sigma_{c x u}+f_{c}\right) \geq-f_{y y c}
$$

Thus, it is possible with the proposed model to evaluate in a simple manner the steel stresses for any combination of concrete normal stresses, and this makes possible to know the whole behavior of the membrane element at failure.

\section{Verification method}

In this section a verification method is presented for the prediction of the ultimate shear stress $\tau_{u}$ of a reinforced concrete membrane given any combination of normal stresses $\sigma_{x d}$ and $\sigma_{y d}$. In this case, the reinforcement ratios $\rho_{x}$ and $\rho_{y}$ are known, as are the concrete and steel material properties. The proposed verification method is based on the proposed simplified model for failure condition of concrete introduced in section 2.4. This method does not need iterations and is straightforward in its application as described below.

The first step involves checking whether any of the design normal stresses can cause the failure of the reinforced concrete membrane in compression or in tension. If this were the case, failure would be caused by normal stresses and the predicted ultimate shear stress would be zero. Hence, in order to continue the method the design normal stresses should satisfy the following expression: 
$-f_{c}-\rho_{x} \cdot f_{y x c} \leq \sigma_{x d} \leq \rho_{x} \cdot f_{y x}$

$-f_{c}-\rho_{y} \cdot f_{y y c} \leq \sigma_{y d} \leq \rho_{y} \cdot f_{y y}$

On the one hand, if the membrane element fails due to crushing of concrete struts with diagonal cracking, the ultimate shear stress is given by Eq. (10) in accordance with the formulation model presented in section 2. Hence:

$\tau_{u}^{d c}=\sqrt{\sigma_{c x u} \cdot \sigma_{c y u}}$

On the other, if the element fails due to crushing of concrete in a biaxial compressive stress state, the ultimate shear stress is given by Eq. (11):

$$
\tau_{u}^{b c}=\sqrt{\left(\sigma_{c x u}+f_{c}\right) \cdot\left(\sigma_{c y u}+f_{c}\right)}
$$

The ultimate concrete stresses $\sigma_{c x u}$ and $\sigma_{c y u}$ required to calculate $\tau_{u}^{d c}$ or $\tau_{u}^{b c}$ (Eq. 23 and 24) can be obtained by substituting the corresponding values of steel stresses $\sigma_{s x}$ and $\sigma_{s y}$ into Eq. (1). These steel stresses can be calculated from (19), (20) and (21) depending on the region of plane $\sigma_{c x}-\sigma_{c y}$ in accordance with the simplified model for failure of concrete described in section 2.4 (Fig. 3).

Given the design normal stresses $\sigma_{x d}$ and $\sigma_{y d}$, the process for establishing the region of the plane $\sigma_{c x}-\sigma_{c y}$ that enables the evaluation of steel stresses $\sigma_{s x}$ and $\sigma_{s y}$ is not a straightforward one. In order to facilitate the choice of region, the region distribution is converted into the plane $\sigma_{x}-\sigma_{y}$ from the original plane $\sigma_{c x^{-}}$ $\sigma_{c y}$, by adding the effect of the steel stress to the ultimate concrete stresses (Fig. 4).

It is important to mention some aspects of the conversion of the region distribution in the plane $\sigma_{x}-\sigma_{y}$. Firstly, lines $(c 1),(c 2)$ change taking into account that the steel reinforcement yields in tension. In contrast, lines $(d 1)$, and $(d 2)$ do not change their position because the steel stresses are zero. Moreover, given the fact that the intersection of curves $(c 1)$ and $(c 2)$ with $-\mathrm{y}$ axis and $-\mathrm{x}$ axis is at $\left(-\mathrm{f}_{\mathrm{c}}\right)$, it is assumed that steel stress is $\mathrm{f}_{\mathrm{yyc}}$ for curve $\left(c 1^{\prime}\right)$ and $\mathrm{f}_{\mathrm{yxc}}$ for curve $\left(c 2^{\prime}\right)$. Thus, these intersection points change their location according to the steel stresses considered. Finally, all these new borders defining each region are extended to the outer rectangle that satisfies Eq. (22), making it possible to choose any combination of normal stresses. 
In this method, the following simple and direct verification can be used to know if the ultimate shear stress will be governed by concrete crushing with diagonal cracking or by concrete crushing in biaxial compression:

$$
\frac{\sigma_{x d}}{-f_{c}-\rho_{x} \cdot f_{y x c}}+\frac{\sigma_{y d}}{-f_{c}-\rho_{y} \cdot f_{y y c}}<1 \rightarrow \text { Concrete crushing with diagonal cracking }
$$

Moreover, the ultimate shear stress predicted through equations (23) and (24) has to be limited to $0.5 f_{c}$. Otherwise, there would be no possible intersection between curves (a) and (b), and the prediction of the ultimate shear stress of the panel would be unrealistic.

In this new interaction diagram it is possible to formulate equations (19) to (21) as functions of the design normal stresses applied by substituting equation (1) into equations (19) to (21). Thus, the following expressions can be derived for each reinforcement direction $i(\mathrm{i}=\mathrm{x}, \mathrm{j}=\mathrm{y}$ or vice versa) reached:

Concrete crushing in biaxial compression:

$$
\sigma_{s i}^{b c}=\frac{n_{i}}{1+n_{i} \cdot \rho_{i}} \cdot \sigma_{i d} \geq-f_{y i c}
$$

Concrete crushing with diagonal cracking:

when $-\alpha_{i} \beta_{j} f_{c}+\rho_{i} f_{y i}<\sigma_{i d} \rightarrow \sigma_{s i 1}^{d c}=f_{y i}$

when $-1.6 \alpha_{i} \beta_{j} f_{c}<\sigma_{i d} \leq-\alpha_{i} \beta_{j} f_{c}+\rho_{i} f_{y i} \rightarrow \sigma_{s i 2}^{d c}=\frac{1.6 \alpha_{i} \beta_{j} f_{c}+\sigma_{i d}}{0.6 \alpha_{i} \beta_{j} f_{c}+\rho_{i} f_{y i}} f_{y i}$

when $\sigma_{i d} \leq-1.6 \alpha_{i} \beta_{j} f_{c} \rightarrow \sigma_{s i 3}^{d c}=\frac{-1.6 \alpha_{i} \beta_{j} f_{c}-\sigma_{i d}+\rho_{i} \sigma_{s i 3}^{d c}}{-1.6 \alpha_{i} \beta_{j} f_{c}+f_{c}+\sigma_{j d}-\rho_{j} \sigma_{s j k}^{d c}} \sigma_{s i, d i a g}^{b c}$

and from Eq. (15) :

$\beta_{j}=\frac{f_{c}+\sigma_{j d}-\rho_{j} \sigma_{s j k}^{d c}}{\left(1-1.6 \alpha_{j}\right) f_{c}} \leq 1_{k=1,2,3}$

The evaluation of $\sigma_{s i 3}^{d c}$ and $\beta_{j}$ requires a numerical analysis with iterations. This could be an option if an exact application of the verification method would be required. In order to facilitate the application of the verification method the following expressions for $\sigma_{s i 3}^{d c}$ and $\beta_{j}$ can be used instead of the original ones. These values are obtained on the basis of the plane $\sigma_{x}-\sigma_{y}$ instead of the plane $\sigma_{c x}-\sigma_{c y}$, while ensuring they do not depend on the normal concrete stresses and/or the steel stresses. These new expressions are 
approximations of the real values but let a direct evaluation of the steel stresses for any region. For the sake of simplicity only the final expressions derived are included in this paper.

$$
\begin{aligned}
& \beta_{j}=\frac{f_{c}+\sigma_{j d}+\rho_{j} f_{y j c}}{\left(1-1.6 \alpha_{j}\right) f_{c}+\rho_{j} f_{y j c}} \leq 1 \\
& \sigma_{s i 3}^{d c}=\left\{\begin{array}{ll}
\frac{\left(\sigma_{i d}+1.6 \alpha_{i} f_{c}\right) f_{y i c}}{\left(1-1.6 \alpha_{i}\right) f_{c}+\rho_{i} f_{y i c}} & \text { if } \sigma_{j d} \geq 0 \\
\frac{\left(\sigma_{i d}+1.6 \alpha_{i} \beta_{j} f_{c}\right) \sigma_{s i d, d i a g}}{\sigma_{i d, d i a g}+1.6 \alpha_{i} \beta_{j} f_{c}} & \text { if } \sigma_{j d}<0
\end{array}\right\} \\
& \sigma_{i d, \text { diag }}=-\frac{f_{c}+\rho_{i} f_{y i c}}{f_{c}+\rho_{j} f_{y j c}}\left(\sigma_{j d}+f_{c}+\rho_{j} f_{y j c}\right) ; \sigma_{s i \text { diag }}=\frac{n_{i} \sigma_{i d, \text { diag }}}{1+n_{i} \rho_{i}} \geq-f_{y i c}
\end{aligned}
$$

At this point, it is important to note that it is possible to obtain the steel stresses in any region without iterations by using a straightforward expression to evaluate them, according to the design normal stresses applied and the material properties of the membrane element. It is also important to highlight that in order to apply the verification method for cases governed by concrete crushing with diagonal cracking, design normal stresses $\sigma_{\mathrm{xd}}$ and $\sigma_{\mathrm{yd}}$ must first satisfy a specific region boundary condition following the interaction diagram presented in Fig. 4, which is also straightforward.

It must be remembered that the following modes of failure are produced in regions A to F: (Region A) reinforcement yields in tension in both directions (Y-Y); (Region $\mathrm{B})$ the reinforcement in direction $-\mathrm{X}$ does not yield and remains in tension, while in direction -y it does yield in tension (T-Y); (Region C), neither type of reinforcement yields and both stay in tension (T-T); (Region D) -x reinforcement does not yield and is in compression, and -y reinforcement yields in tension (C-Y); (Region E) - $\mathrm{x}$ reinforcement does not yield and is in compression, while the reinforcement in the $-\mathrm{y}$ direction does not yield either but remains in tension $(\mathrm{C}-\mathrm{T})$; and (Region $\mathrm{F}$ ) reinforcement does not yield and remains in compression for both directions.

Overall, the practical application of the proposed verification method is summarized in the flowchart shown in Fig. 5.

\section{Experimental verification}

The proposed verification method has been used to predict the ultimate shear stress and the mode of failure of 88 specimens tested by different researchers. Only specimens with an experimental mode of failure supported by the model proposed have been included for validation. Table 1 shows the designation 
of the specimens tested and the number of tests included for validation for each research team. Further information regarding the experimental data and results used in this section can be found in Annex 1. It is worth noting that in the shear plane of pushoff tests there exists not only shear stress but also a normal compressive stress $\sigma_{x}$. According to Rahal (2010) [15] the calculation of $\sigma_{x}$ in the shear plane is not simple and neglecting $\sigma_{x}$ provides conservative results. As a result, normal stress $\sigma_{x}$ has been considered zero in all the experimental validations by Hofbeck et al [7] (see Annex 1).

The comparison between the experimental ultimate shear stress $\left(\tau_{\mathrm{u}, \mathrm{exp}}\right)$ and that predicted by the proposed method $\left(\tau_{\mathrm{u}, \mathrm{cal}}\right)$ is shown in Fig. 6 and also in Annex 1. In this figure, results are grouped by mode of failure: region $\mathrm{A}(\mathrm{Y}-\mathrm{Y})$, region $\mathrm{B}(\mathrm{T}-\mathrm{Y})$, and region $\mathrm{C}(\mathrm{T}-\mathrm{T})$. It is important to note that the literature does not include any experimental tests corresponding to any of the other regions. As a result, no experimental validation of the proposed method has been possible.

Moreover, Table 2 includes some statistical values to show the behavior predicted with the proposed method compared to the experimental results obtained. This table also includes comparisons of the proposed method with other simplified methods that will be discussed in section 6 .

Despite the simplicity of the method, reasonable accuracy with a mean value of 1.05 and a coefficient of variation of $14.6 \%$ can be observed for all the specimens considered. Regarding the mode of failure, the method predicts mean values greater than 1 for regions A and B, and less than 1 for region $\mathrm{C}$. Another key aspect to be studied is the comparison between the modes of failure observed in the laboratory and those predicted by the method proposed. In Table 3 this comparison is shown and extended only to specimens in which the experimental mode of failure was reported. The accuracy obtained is high because the mode of failure has been predicted to a percentage of $87 \%$. It is important to emphasize that for some of the panels where the mode of failure was not properly predicted the error in the determination of steel stresses was similar to the error obtained for other panels where the mode of failure was well predicted. These results confirm that for the range of panels compared the accuracy of the proposed method is quite high despite its simplicity.

Finally, steel stresses calculated with the proposed method have been compared with stresses obtained experimentally. It has only been possible to compare those specimens in which strains measurements in the reinforcement directions had been registered. Experimental stresses are obtained in an approximate way. In all cases it is assumed a Young modulus for steel $\mathrm{E}_{\mathrm{s}}=200000 \mathrm{MPa}$ and steel stress is limited to its corresponding steel yield stress. The results of this comparison are shown in Table 4 and include a total of 
57 specimens. The scatter of results of steel stress predictions is high, even though in a significant number of cases yielding of the reinforcement is both obtained experimentally and with the proposed method.

Moreover, it is interesting to study the accuracy that the steel stresses prediction presents and its influence on the ultimate shear stress. To this end, it is also included in Table 4 the ultimate shear stress obtained in the laboratory $\tau_{u, e x p}$, the ultimate shear stress predicted by the proposed method $\tau_{u, c a l}$, and the ultimate shear stress predicted by the proposed method according to Eq. (23) but considering the values of the

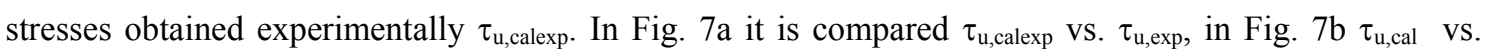
$\tau_{u, \text { calexp }}$, and in Fig. $7 c \tau_{u, \text { cal }}$ vs. $\tau_{u, \text { exp }}$. In the first comparison (Fig. $7 \mathrm{a}$ ), the ultimate shear stress $\tau_{u, \text { calexp }}$ is underestimated in comparison with $\tau_{\mathrm{u}, \text { exp }}$ with a mean value of 0.86 and a $\mathrm{CV}=16.39 \%$. This result makes sense given the fact that other mechanisms apart from reinforcement play a role in the ultimate shear stress of the panels. In the second comparison (Fig. 7b), it is shown that the proposed method overestimates the ultimate shear stress compared with steel stresses obtained experimentally with a mean value of 1.12 and a $\mathrm{CV}=14.45 \%$. This result also makes sense since there are mechanisms of shear transfer that have been neglected in the simplified method proposed. Finally, in the third comparison (Fig. 7c), a good accuracy of the method proposed can be observed compared with the experimental results, with a mean value of 0.95 and a $\mathrm{CV}=11.47 \%$. This latter result remains in between the first and the second results. It is worth noting that a significant poor prediction of steel stress not necessarily results in a poor prediction of the ultimate shear stress.

\section{Numerical validation}

The proposed verification method has been formulated to predict the ultimate shear stress of reinforced concrete membrane elements for any combination of normal stresses. Nevertheless, the experimental verification has demonstrated that the method provides good predictions only in regions A, $\mathrm{B}$, and $\mathrm{C}$. There are some other regions in which no experimental results have been reported so far.

A comparison with a well-known material model like MCFT makes it possible to study whether predictions of the verification method are good enough in regions with no experimental tests reported. The program Membrane-2000 includes the behavior of MCFT and is available online [3]. A comparison was carried out using the input data corresponding to specimen PV-20, included in Membrane-2000, and used to demonstrate how this software works. 
For specimen PV-20, an extensive bunch of combinations of normal stresses was chosen. The normal stress $\sigma_{\mathrm{xd}}$ ranged between -26.0 MPa and $8 \mathrm{MPa}$, while normal stress $\sigma_{\mathrm{yd}}$ ranged between -22.0 MPa and 2 MPa. For each normal stress, a variation of $2 \mathrm{MPa}$ intervals resulted in 234 different combinations included in all of the regions described in the verification method.

Predictions of the ultimate shear stress according to Membrane-2000 and the proposed verification method were carried out for all 234 combinations. For each method a 3D surface plot is included in Fig. 8 to show the prediction of the ultimate shear stress of the panel for all the combinations of normal stresses. All the graphs shown make use of an interpolation function to plot the 3D surface, which should be reasonably accurate given the fact that the number of combinations of normal stresses considered is high and uniformly smeared. In both graphs it can be observed that the overall shape of the surface is quite similar, even though major differences can be observed on the edges of the graph. In both cases the part of the surface governed by a diagonal cracking mode of failure and the part with dominant concrete crushing in biaxial compression can be seen. It is interesting to note that when normal compression stresses are dominant the proposed method gives lower predictions than those obtained with Membrane2000. For example, the maximum ultimate shear stress predicted in Membrane-2000 is $10.3 \mathrm{MPa}$, while in the proposed method it is $9.8 \mathrm{MPa}$, limiting the value to the maximum possible, $0.5 \mathrm{f}_{\mathrm{c}}$, as stated in section 3. Thus, the proposed method is on the safe side compared to Membrane-2000 when compression normal stresses are dominant. This makes sense given the type of simplification considered in the development of this method. Finally, in Fig. 9 the difference between the predictions of the two methods is shown. This graph shows part of the total combinations employed, and a reasonable approximation is achieved.

\section{Comparison with other simplified methods}

Finally, the results in the literature for the 88 specimens (Table 1) with the proposed verification method have also been compared with the following simplified methods proposed by Kaufmann and Marti (1998) [11], Carbone, Giordano and Mancini (2001) [4], and Rahal (2008) [16]. Table 5 summarizes the formulation of the three methods in order to show how we have implemented these methods for comparison. Moreover, Annex I shows the comparison between the different simplified methods for all the specimens considered, and the experimental ultimate shear stress $\left(\tau_{\mathrm{u}, \exp }\right)$ in comparison with the ultimate shear stress predicted by each simplified method $\left(\tau_{\mathrm{u}, \mathrm{cal}}\right)$. Moreover, Table 2 includes some statistical values to show the behavior achieved with each of the methods. All these results have been 
grouped in terms of the mode of failure according to the prediction of the verification method proposed in this paper. For the specific case of region A (yielding of reinforcement in tension in both directions, YY), the four methods show the same mean value and the same variation coefficient. In these regions the four methods employed predict exactly the same results except for specimen HB4 tested by Hsu TTC, Zhang L [8]. However, the methods by Kaufmann and Marti (1998) [11] and Carbone, Giordano and Mancini (2001) [4] predict the same mode of failure as that detected in the laboratory (region 2, T-Y), see Table 3. For the case of region $\mathrm{B}(\mathrm{T}-\mathrm{Y})$ and region $\mathrm{C}(\mathrm{T}-\mathrm{T})$, the proposed verification method shows a minor scatter of results $\left(\tau_{\exp } / \tau_{\text {cal }}\right)$ closer to 1 , and with the lowest coefficient of variation in comparison with the other simplified methods considered. Regarding the overall comparison including the bulk of the experimental data, the proposed verification method has an average error which is closer to 1 , the lowest coefficient of variation, a $5 \%$ percentile similar to all the other simplified methods, and greater accuracy in regions B (T-Y) and C (T-T). Moreover, the modes of failure registered in the experimental tests and the modes of failure predicted by the simplified method proposed in this paper, and also with the simplified methods by Kaufmann and Marti (1998) [11], Carbone, Giordano and Mancini (2001) [4], and Rahal (2008) [16] are compared in Table 3. The accuracy achieved with the proposed method is $87 \%$, while with Kaufmann and Marti (1998) [11] is 84\%, with Carbone, Giordano and Mancini (2001) [4] is $84 \%$ and with Rahal (2008) [16] is $90 \%$. In all these cases, the accuracy is high and greater than $84 \%$.

\section{Conclusions}

A simple verification method for predicting the ultimate shear stress and the mode of failure of reinforced concrete membranes has been presented in this paper. This method, based on a simplified model for considering concrete behavior at failure, is straightforward and no iterative processes are required. It can be applied under any normal stress combination with any combination of reinforcement ratios in both orthogonal directions and can also predict the steel stresses of reinforcement both in tension and compression, as well as distinguishing whether yielding is reached. Thus, with this method it is possible to establish a rational classification of modes of failure.

The proposed verification method provides good agreement with the 88 experimental tests selected, which cover different modes of failure, a wide range of reinforcement ratios, and several material strengths. Accuracy is high in terms of ultimate shear stress and mode of failure.

Since the experimental validation only covers the most common modes of failure, the method has been validated extensively for the entire range of normal stresses by carrying out comparisons using 
Membrane-2000 software, which includes the MCFT material model. The comparison shows good accuracy in terms of ultimate shear stress predicted, and the shape of the failure surface predicted in both cases is very similar.

The proposed verification method was also compared with the simplified methods by Kaufmann and Marti (1998) [11], Carbone, Giordano and Mancini (2001) [4], and with the SMCS by Rahal (2008) [16] and showed the lowest mean value and coefficient of variation compared to the experimental results considered, especially in the predictions where at least one reinforcement did not yield.

\section{Acknowledgments}

The authors of this work wish to thank the research bureau of the Spanish Ministry of Science and Innovation for the funding of the projects BIA 2009-10207 and BIA 2009-11369, and the Universitat Politècnica de València for the funding through the Programa de Apoyo a la Investigación y Desarrollo (PAID-06-11).

\section{References}

[1] AASHTO LRFD Bridge Design Specifications. American Association of State Highway and Transportation Officials (AASHTO). 2010.

[2] Bentz EC, Vecchio FJ, Collins MP. Simplified modified compression field theory for calculating shear strength of reinforced concrete elements. ACI Structural Journal 2006; 103(6):614-24

[3] Bentz, E. C., Membrane-2000, http://www.ecf.utoronto.ca/ bentz/m2k.htm. (last accessed Apr. 5, 2012)

[4] Carbone VI, Giordano L, Mancini G. Design of RC membrane elements. Structural Concrete 2001; 2(4):213-23

[5] CSA-A23.3. Design of concrete structures (A.23.3-04). Canadian Standards Association. 2004

[6] Eurocode 2. Design of concrete structures - Part 2: Concrete bridges - Design and detailing rules (EN 1992-2). 2005.

[7] Hofbeck JA, Ibrahim IO, Mattock AH. Shear transfer in reinforced concrete. ACI Journal 1969; 66(1):119-28.

[8] Hsu TTC, Zhang L. Nonlinear analysis of membrane elements by fixed-angle softened-truss model. ACI Structural Journal 1997; 94(4):483-91.

[9] Hsu TTC. Nonlinear analysis of concrete membrane elements. ACI Structural Journal 1991; 88(5):552-61

[10] Hsu TTC. Toward a unified nomenclature for reinforced concrete theory. Journal of Structural Engineering 1996; 122(3):275-83

[11] Kaufmann W, Marti P. Structural concrete: cracked membrane model. Journal of Structural Engineering 1998; 124(12):1467-75

[12] Marti P, Meyboom J. Response of prestressed concrete elements to in-plane shear forces. ACI Structural Journal 1992; 89(4):503-14.

[13] Pang X., Hsu TTC. Behaviour of reinforced concrete membrane elements in shear. ACI Structural Journal 1995; 92(6):665-77.

[14] Rahal KN. Shear transfer of reinforced concrete: Part I-Membrane elements subjected to pure shear. ACI Structural Journal 2000; 97(4):86-94 
[15] Rahal KN. Shear transfer strength of reinforced concrete. ACI Structural Journal 2010; 107(4):419-26

[16] Rahal KN. Simplified design and capacity calculation of shear strength in reinforced concrete membrane elements. Engineering Structures 2008; 30(10):2782-91.

[17] Vecchio FJ, Collins MP, Aspiotis J. High strength concrete elements subjected to shear. ACI Structural Journal 1994; 91(4):423-32.

[18] Vecchio FJ, Collins MP. The modified compression-field theory for reinforced concrete elements subjected to shear. ACI Journal 1986; 83(2):219-31

[19] Vecchio FJ. Disturbed stress field model for reinforced concrete: Formulation. Journal of Structural Engineering 2000; 126(9):1070:77

[20] Vecchio FJ. Disturbed stress field model for reinforced concrete: Implementation. Journal of Structural Engineering 2001; 127(1):12:20

[21] Xie L, Benz EC, Collins MP. Influence of axial stress on shear response of reinforced concrete elements. ACI Structural Journal 2011; 108(6):745-54 


\section{Notation}

$$
\begin{array}{ll}
\sigma_{x}, \sigma_{y}, \tau_{x y} & \text { Normal and shear stresses applied to membrane } \\
\sigma_{x d}, \sigma_{y d}, \tau_{d} & \text { Normal and shear design stresses applied to membrane } \\
\sigma_{c x}, \sigma_{c y}, \tau_{c x y} & \text { Average normal and shear stresses resisted by concrete } \\
\sigma_{c x u}, \sigma_{c y u} & \text { Normal stresses resisted by concrete at failure } \\
\sigma_{s x}, \sigma_{s y} & \text { Average steel stresses in x and y directions }
\end{array}
$$

Reinforcement ratios in $\mathrm{x}$ and $\mathrm{y}$ directions

$\sigma_{c 1}, \sigma_{c 2}$

$\theta_{\sigma}$

$\varepsilon_{c x}, \varepsilon_{c y}$

$\varepsilon_{s x}, \varepsilon_{s y}$

$\varepsilon_{1}, \varepsilon_{2}$

$\theta_{\varepsilon}$

$\xi$

$f_{c}$

$f_{y i}$

$f_{y i c}$

$\varepsilon_{c 0}$

$\varepsilon_{y i}$

$E_{c, \text { sec }}$

$E_{s}$

Principal stresses in concrete $\left(\sigma_{c 1}>\sigma_{c 2}\right)$

Inclination of the minor principal stress of concrete

Average concrete strains in $\mathrm{x}$ and $\mathrm{y}$ directions

Average steel strains in $\mathrm{x}$ and $\mathrm{y}$ directions

Principal strains of the membrane element

Inclination of the minor principal strain of concrete

Softening factor to reduce compressive strength of diagonal cracked concrete

Cylinder compressive strength of concrete

Tension yield stress of the reinforcement in i-direction

Strength of steel in compression in i-direction

Peak strain of concrete

Yield strain of the reinforcement in i-direction

Secant modulus of elasticity for concrete at failure

Modulus of elasticity of steel

Ultimate shear stress predicted for concrete crushing with biaxial compression

Ultimate shear stress predicted for concrete crushing with diagonal cracking 


\section{List of Tables}

Table 1 Experimental tests used to validate the verification method

1.1 Table 2 Experimental verification: ultimate shear stress

Table 3 Experimental verification: mode of failure

2.2

Table 4 Experimental verification: steel stresses

Table 5 Simplified methods proposed by other authors 


\section{List of figures}

Figure 1 Stress and strain states of a membrane element. Mohr circle for concrete stresses and strains

Figure 2 Interaction diagram for concrete crushing $\left(\sigma_{\mathrm{cx}}-\sigma_{\mathrm{cy}}\right)$ in a $\mathrm{RC}$ membrane element

Figure 3 Simplified interaction diagram for concrete crushing $\left(\sigma_{\mathrm{cx}}-\sigma_{\mathrm{cy}}\right)$ in a $\mathrm{RC}$ membrane element

Figure 4 Simplified interaction diagram for concrete crushing $\left(\sigma_{x}-\sigma_{y}\right)$ in a RC membrane element

Figure 5 Simplified verification method for RC membrane elements

1.1 Figure 6 Predicted vs. experimental ultimate shear stress

2.2 Figure 7 Influence of steel stresses on ultimate shear stress predictions

1.1

Figure 8 Ultimate shear stress predicted by Membrane-2000 and the verification method

Figure 9 Difference in ultimate shear stress between Membrane-2000 and the verification method 


\begin{tabular}{llc}
\hline \multicolumn{1}{c}{ Research team } & \multicolumn{1}{c}{ Specimen designation } & Number \\
\hline Vecchio FJ, Collins MP [18] & PV1, ., PV30 & 18 \\
Hofbeck JA, Ibrahim IO, Mattock AH [7] & $1.1 \mathrm{~A}, \ldots, 6.4$ & 37 \\
Pang X, Hsu TTC [13] & A1, ., , A4, B1, .., B6 & 10 \\
Hsu TTC, Zhang L [8] & HB1, HB3, HB4 & 3 \\
Marti P, Meyboom J [12] & PP1, PP2, PP3 & 3 \\
Vecchio FJ, Collins MP, Aspiotis J [17] & PHS2, .., PHS10, PA1, PA2 & 11 \\
Xie L, Bentz EC, Collins MP [21] & PL1,..PL6 & 6 \\
\hline
\end{tabular}

Table 1 


\begin{tabular}{|c|c|c|c|c|c|c|c|}
\hline \multirow{2}{*}{$\begin{array}{c}\text { Mode of } \\
\text { Failure } \\
\text { (Predicted) }\end{array}$} & \multirow[t]{2}{*}{ Region } & \multirow[t]{2}{*}{ No. } & \multirow{2}{*}{$\begin{array}{l}\text { Statistical } \\
\text { values }\end{array}$} & \multicolumn{4}{|c|}{ Simplified Method } \\
\hline & & & & Proposed & $\begin{array}{l}\text { Kaufmann } \\
\text { and Marti }\end{array}$ & $\begin{array}{c}\text { Carbone } \\
\text { et al. }\end{array}$ & Rahal \\
\hline \multirow{6}{*}{$\mathrm{Y}-\mathrm{Y}$} & \multirow{6}{*}{ A } & \multirow{6}{*}{17} & Average $\left(\tau_{\text {exp }} / \tau_{\text {cal }}\right)$ & 1.06 & 1.06 & 1.06 & 1.06 \\
\hline & & & C.V. & 0.18 & 0.17 & 0.17 & 0.18 \\
\hline & & & Max & 1.67 & 1.67 & 1.67 & 1.67 \\
\hline & & & Percentile (95\% ) & 1.29 & 1.29 & 1.29 & 1.29 \\
\hline & & & Percentile (5\%) & 0.87 & 0.91 & 0.91 & 0.87 \\
\hline & & & Min & 0.86 & 0.86 & 0.86 & 0.86 \\
\hline \multirow{6}{*}{$\mathrm{T}-\mathrm{Y}$} & \multirow{6}{*}{ B } & \multirow{6}{*}{57} & Average $\left(\tau_{\text {exp }} / \tau_{\text {cal }}\right)$ & 1.05 & 1.17 & 1.21 & 1.12 \\
\hline & & & C.V. & 0.15 & 0.19 & 0.17 & 0.16 \\
\hline & & & Max & 1.45 & 1.76 & 1.82 & 1.61 \\
\hline & & & Percentile (95\%) & 1.31 & 1.71 & 1.56 & 1.40 \\
\hline & & & Percentile (5\%) & 0.86 & 0.92 & 0.97 & 0.87 \\
\hline & & & Min & 0.57 & 0.68 & 0.72 & 0.64 \\
\hline \multirow{6}{*}{$\mathrm{T}-\mathrm{T}$} & \multirow{6}{*}{$\mathrm{C}$} & \multirow{6}{*}{14} & Average $\left(\tau_{\text {exp }} / \tau_{\text {cal }}\right)$ & 1.02 & 1.13 & 1.05 & 1.13 \\
\hline & & & C.V. & 0.10 & 0.16 & 0.11 & 0.15 \\
\hline & & & Max & 1.22 & 1.47 & 1.19 & 1.52 \\
\hline & & & Percentile (95\% ) & 1.18 & 1.41 & 1.19 & 1.44 \\
\hline & & & Percentile (5\%) & 0.87 & 0.90 & 0.89 & 0.96 \\
\hline & & & Min & 0.86 & 0.85 & 0.87 & 0.93 \\
\hline \multirow{6}{*}{ All } & & \multirow{6}{*}{88} & Average $\left(\tau_{\text {exp }} / \tau_{\text {cal }}\right)$ & 1.05 & 1.14 & 1.16 & 1.11 \\
\hline & & & C.V. & 0.15 & 0.19 & 0.18 & 0.16 \\
\hline & & & Max & 1.67 & 1.76 & 1.82 & 1.67 \\
\hline & & & Percentile (95\% ) & 1.29 & 1.64 & 1.52 & 1.43 \\
\hline & & & Percentile (5\%) & 0.87 & 0.90 & 0.91 & 0.87 \\
\hline & & & Min & 0.57 & 0.68 & 0.72 & 0.64 \\
\hline
\end{tabular}

Table 2 


\begin{tabular}{|c|c|c|c|c|c|c|c|c|c|c|c|}
\hline Spec. & Exp. & Proposed & $\begin{array}{l}\text { Kaufmann } \\
\text { and Marti }\end{array}$ & $\begin{array}{l}\text { Carbone } \\
\text { et al. }\end{array}$ & Rahal & Spec. & Exp. & Proposed & $\begin{array}{c}\text { Kaufmann } \\
\text { and Marti }\end{array}$ & $\begin{array}{l}\text { Carbone } \\
\text { et al. }\end{array}$ & Rahal \\
\hline A1 & $\mathrm{Y}-?$ & $\mathrm{Y}-\mathrm{Y}$ & $\mathrm{Y}-\mathrm{Y}$ & $Y-Y$ & $Y-Y$ & PA2 & $\mathrm{T}-\mathrm{Y}$ & Y-Y & Y-Y & $Y-Y$ & $\mathrm{Y}-\mathrm{Y}$ \\
\hline A2 & $Y-Y$ & Y-Y & Y-Y & Y-Y & Y-Y & PV4 & $Y-Y$ & Y-Y & Y-Y & Y-Y & Y-Y \\
\hline A3 & $\mathrm{Y}-\mathrm{Y}$ & Y-Y & Y-Y & Y-Y & Y-Y & PV6 & $Y-Y$ & Y-Y & Y-Y & Y-Y & Y-Y \\
\hline A4 & $\mathrm{Y}-\mathrm{Y}$ & T-T & Y-T & Y-T & T-T & PV9 & $\mathrm{T}-\mathrm{T}$ & $\mathrm{T}-\mathrm{T}$ & Y-T & Y-T & $\mathrm{T}-\mathrm{T}$ \\
\hline B1 & $\mathrm{Y}-\mathrm{Y}$ & Y-Y & Y-Y & Y-Y & Y-Y & PV10 & $\mathrm{T}-\mathrm{Y}$ & $\mathrm{T}-\mathrm{Y}$ & $\mathbf{Y}-\mathrm{Y}$ & $\mathbf{Y}-\mathrm{Y}$ & $\mathrm{T}-\mathrm{Y}$ \\
\hline B2 & Y-Y & Y-Y & $Y-Y$ & $Y-Y$ & $Y-Y$ & PV11 & $\mathrm{Y}-\mathrm{Y}$ & $Y-Y$ & $Y-Y$ & $Y-Y$ & Y-Y \\
\hline B3 & $Y-Y$ & $Y-Y$ & $Y-Y$ & $Y-Y$ & $Y-Y$ & PV12 & $\mathrm{T}-\mathrm{Y}$ & $\mathrm{T}-\mathrm{Y}$ & $\mathrm{T}-\mathrm{Y}$ & $\mathrm{T}-\mathrm{Y}$ & $\mathrm{T}-\mathrm{Y}$ \\
\hline B4 & $\mathrm{T}-\mathrm{Y}$ & $\mathrm{T}-\mathrm{Y}$ & $\mathrm{T}-\mathrm{Y}$ & $\mathrm{T}-\mathrm{Y}$ & $\mathrm{T}-\mathrm{Y}$ & PV16 & $Y-Y$ & $Y-Y$ & Y-Y & $Y-Y$ & $Y-Y$ \\
\hline B5 & $\mathrm{T}-\mathrm{Y}$ & $\mathrm{T}-\mathrm{Y}$ & $\mathrm{T}-\mathrm{Y}$ & $\mathrm{T}-\mathrm{Y}$ & $\mathrm{T}-\mathrm{Y}$ & PV19 & $\mathrm{T}-\mathrm{Y}$ & $\mathrm{T}-\mathrm{Y}$ & $\mathrm{T}-\mathrm{Y}$ & $\mathrm{T}-\mathrm{Y}$ & T-Y \\
\hline B6 & $\mathrm{T}-\mathrm{Y}$ & T-Y & $\mathrm{T}-\mathrm{Y}$ & $\mathrm{T}-\mathrm{Y}$ & $\mathrm{T}-\mathrm{Y}$ & PV20 & $\mathrm{T}-\mathrm{Y}$ & $\mathrm{T}-\mathrm{Y}$ & $\mathrm{T}-\mathrm{Y}$ & $\mathrm{T}-\mathrm{Y}$ & $\mathrm{T}-\mathrm{Y}$ \\
\hline HB1 & $Y-Y$ & Y-Y & $Y-Y$ & $Y-Y$ & $Y-Y$ & PV21 & $\mathrm{T}-\mathrm{Y}$ & $\mathrm{T}-\mathrm{Y}$ & $\mathrm{T}-\mathrm{Y}$ & $\mathrm{T}-\mathrm{Y}$ & $\mathrm{T}-\mathrm{Y}$ \\
\hline HB3 & $Y-Y$ & $Y-Y$ & Y-Y & $Y-Y$ & $Y-Y$ & PV22 & $\mathrm{T}-\mathrm{T}$ & $\mathrm{T}-\mathrm{T}$ & Y-T & Y-T & $\mathrm{T}-\mathrm{T}$ \\
\hline HB4 & $\mathrm{T}-\mathrm{Y}$ & $\mathbf{Y}-\mathrm{Y}$ & $\mathrm{T}-\mathrm{Y}$ & $\mathrm{T}-\mathrm{Y}$ & $\mathrm{T}-\mathrm{Y}$ & PV23 & $\mathrm{T}-\mathrm{T}$ & $\mathrm{T}-\mathrm{T}$ & $\mathbf{Y}-\mathrm{T}$ & $\mathbf{Y}-\mathrm{T}$ & $\mathrm{T}-\mathrm{T}$ \\
\hline PP1 & $\mathrm{T}-\mathrm{Y}$ & $\mathrm{T}-\mathrm{Y}$ & $\mathrm{T}-\mathrm{Y}$ & $\mathrm{T}-\mathrm{Y}$ & $\mathrm{T}-\mathrm{Y}$ & PV24 & $\mathrm{C}-\mathrm{C}$ & T-T & Y-T & Y-T & T-T \\
\hline PP2 & $Y-Y$ & T-Y & Y-Y & Y-Y & Y-Y & PV25 & $\mathrm{T}-\mathrm{T}$ & $\mathrm{T}-\mathrm{T}$ & Y-T & Y-T & $\mathrm{T}-\mathrm{T}$ \\
\hline PP3 & $Y-Y$ & T-Y & Y-Y & $Y-Y$ & $Y-Y$ & PV26 & $\mathrm{T}-\mathrm{Y}$ & $\mathrm{T}-\mathrm{Y}$ & $\mathrm{T}-\mathrm{Y}$ & $\mathrm{T}-\mathrm{Y}$ & T-Y \\
\hline PHS2 & $\mathrm{T}-\mathrm{Y}$ & $\mathrm{T}-\mathrm{Y}$ & $\mathrm{T}-\mathrm{Y}$ & T-Y & $\mathrm{T}-\mathrm{Y}$ & PV27 & $\mathrm{T}-\mathrm{T}$ & $\mathrm{T}-\mathrm{T}$ & Y-T & Y-T & $\mathrm{T}-\mathrm{T}$ \\
\hline PHS3 & $\mathrm{T}-\mathrm{Y}$ & $\mathrm{T}-\mathrm{Y}$ & $\mathrm{T}-\mathrm{Y}$ & T-Y & $\mathrm{T}-\mathrm{Y}$ & PV28 & $\mathrm{T}-\mathrm{T}$ & $\mathrm{T}-\mathrm{T}$ & Y-T & Y-T & $\mathrm{T}-\mathrm{T}$ \\
\hline PHS4 & $\mathrm{T}-\mathrm{Y}$ & $\mathrm{T}-\mathrm{Y}$ & $\mathrm{T}-\mathrm{Y}$ & T-Y & $\mathrm{T}-\mathrm{Y}$ & PV29 & $\mathrm{T}-\mathrm{Y}$ & $\mathrm{T}-\mathrm{Y}$ & $\mathrm{T}-\mathrm{Y}$ & $\mathrm{T}-\mathrm{Y}$ & $\mathrm{T}-\mathrm{Y}$ \\
\hline PHS5 & $\mathrm{T}-\mathrm{Y}$ & $\mathrm{T}-\mathrm{Y}$ & T-Y & $\mathrm{T}-\mathrm{Y}$ & $\mathrm{T}-\mathrm{Y}$ & PL1 & $\mathrm{T}-\mathrm{Y}$ & $\mathrm{T}-\mathrm{Y}$ & T-Y & $\mathrm{T}-\mathrm{Y}$ & T-Y \\
\hline PHS6 & $\mathrm{T}-\mathrm{Y}$ & T-Y & $\mathrm{T}-\mathrm{Y}$ & T-Y & $\mathrm{T}-\mathrm{Y}$ & PL2 & $\mathrm{T}-\mathrm{Y}$ & $\mathrm{T}-\mathrm{Y}$ & $\mathrm{T}-\mathrm{Y}$ & $\mathrm{T}-\mathrm{Y}$ & $\mathrm{T}-\mathrm{Y}$ \\
\hline PHS7 & $\mathrm{T}-\mathrm{Y}$ & $\mathrm{T}-\mathrm{Y}$ & $\mathrm{T}-\mathrm{Y}$ & $\mathrm{T}-\mathrm{Y}$ & $\mathrm{T}-\mathrm{Y}$ & PL3 & $\mathrm{T}-\mathrm{Y}$ & Y-Y & Y-Y & $\mathbf{Y}-\mathbf{Y}$ & $\mathbf{Y}-\mathrm{Y}$ \\
\hline PHS8 & $\mathrm{T}-\mathrm{Y}$ & $\mathrm{T}-\mathrm{Y}$ & $\mathrm{T}-\mathrm{Y}$ & $\mathrm{T}-\mathrm{Y}$ & $\mathrm{T}-\mathrm{Y}$ & PL4 & C-T & T-Y & T-Y & T-Y & T-Y \\
\hline PHS9 & $\mathrm{T}-\mathrm{Y}$ & $\mathrm{T}-\mathrm{Y}$ & $\mathrm{T}-\mathrm{Y}$ & $\mathrm{T}-\mathrm{Y}$ & $\mathrm{T}-\mathrm{Y}$ & PL5 & $\mathrm{T}-\mathrm{Y}$ & $\mathrm{T}-\mathrm{Y}$ & $\mathrm{T}-\mathrm{Y}$ & $\mathrm{T}-\mathrm{Y}$ & $\mathrm{T}-\mathrm{Y}$ \\
\hline PHS10 & $\mathrm{T}-\mathrm{Y}$ & T-Y & $\mathrm{T}-\mathrm{Y}$ & $\mathrm{T}-\mathrm{Y}$ & $\mathrm{T}-\mathrm{Y}$ & PL6 & $\mathrm{Y}-\mathrm{Y}$ & $Y-Y$ & Y-Y & Y-Y & Y-Y \\
\hline PA1 & $\mathrm{T}-\mathrm{Y}$ & Y-Y & $\mathbf{Y}-\mathrm{Y}$ & $\mathbf{Y}-\mathrm{Y}$ & $\mathbf{Y}-\mathrm{Y}$ & & & & & & \\
\hline
\end{tabular}

Table 3 


\begin{tabular}{|c|c|c|c|c|c|c|c|c|c|}
\hline Specimen & $\varepsilon_{x, \exp }$ & $\varepsilon_{y, \exp }$ & $\begin{array}{l}\sigma_{s x, \exp }^{a p r o x} \\
(\mathrm{MPa})\end{array}$ & $\begin{array}{l}\sigma_{s y, \exp }^{a p r o x} \\
(\mathrm{MPa})\end{array}$ & $\begin{array}{c}\sigma_{s x, c a l c} \\
(\mathrm{MPa})\end{array}$ & $\begin{array}{c}\sigma_{\text {sy,calc }} \\
(\mathrm{MPa})\end{array}$ & $\frac{\tau_{u, \text { cal } \exp }}{\tau_{u, \exp }}$ & $\frac{\tau_{u, c a l}}{\tau_{u, c a l \text { exp }}}$ & $\frac{\tau_{u, c a l}}{\tau_{u, \exp }}$ \\
\hline A1 & 0.00251 & - & 444.90 & - & 444.90 & 444.90 & & & \\
\hline A2 & 0.01225 & 0.01426 & 462.80 & 462.80 & 462.80 & 462.80 & 1.03 & 1.00 & 1.03 \\
\hline A3 & 0.00610 & 0.00590 & 446.50 & 446.50 & 446.50 & 446.50 & 1.04 & 1.00 & 1.04 \\
\hline A4 & 0.00272 & 0.00251 & 469.90 & 469.90 & 404.63 & 404.63 & 1.24 & 0.86 & 1.07 \\
\hline B1 & 0.00623 & 0.01750 & 462.80 & 444.90 & 462.80 & 444.90 & 0.96 & 1.00 & 0.96 \\
\hline B2 & 0.00464 & 0.00962 & 446.60 & 462.90 & 446.60 & 462.90 & 1.08 & 1.00 & 1.08 \\
\hline B3 & 0.00309 & 0.00849 & 446.50 & 444.90 & 446.50 & 444.90 & 1.05 & 1.00 & 1.05 \\
\hline B4 & 0.00076 & 0.01070 & 152.00 & 444.90 & 424.39 & 444.90 & 0.68 & 1.67 & 1.14 \\
\hline B5 & 0.00137 & 0.00746 & 274.00 & 462.80 & 406.85 & 462.80 & 0.94 & 1.22 & 1.14 \\
\hline B6 & 0.00172 & 0.00593 & 344.00 & 446.60 & 407.73 & 446.60 & 0.99 & 1.09 & 1.08 \\
\hline PP1 & 0.00165 & 0.00824 & 330.00 & 480.00 & 401.69 & 480.00 & 0.90 & 1.10 & 0.99 \\
\hline PP2 & 0.00291 & 0.00826 & 486.00 & 480.00 & 429.11 & 480.00 & 0.93 & 0.95 & 0.88 \\
\hline PP3 & 0.00343 & 0.00812 & 480.00 & 480.00 & 478.19 & 480.00 & 0.88 & 1.00 & 0.88 \\
\hline PHS2 & 0.00216 & 0.01628 & 432.00 & 521.00 & 520.13 & 521.00 & 0.82 & 1.10 & 0.90 \\
\hline PHS3 & 0.00157 & 0.00553 & 314.00 & 521.00 & 479.23 & 521.00 & 0.80 & 1.24 & 0.99 \\
\hline PHS4 & 0.00182 & 0.01107 & 364.00 & 521.00 & 563.10 & 521.00 & 0.73 & 1.28 & 0.94 \\
\hline PHS5 & 0.00141 & 0.01393 & 282.00 & 521.00 & 462.88 & 521.00 & 0.56 & 1.32 & 0.74 \\
\hline PHS6 & 0.00176 & 0.00964 & 352.00 & 521.00 & 378.57 & 521.00 & 0.81 & 1.03 & 0.83 \\
\hline PHS7 & 0.00137 & 0.00310 & 274.00 & 521.00 & 408.72 & 521.00 & 0.86 & 1.18 & 1.01 \\
\hline PHS8 & 0.00239 & 0.00988 & 478.00 & 521.00 & 476.32 & 521.00 & 0.92 & 1.00 & 0.92 \\
\hline PHS9 & 0.00173 & 0.00947 & 346.00 & 521.00 & 402.47 & 521.00 & 0.83 & 1.07 & 0.88 \\
\hline PHS10 & 0.00208 & 0.00793 & 416.00 & 521.00 & 485.37 & 521.00 & 0.81 & 1.09 & 0.89 \\
\hline PA1 & 0.00223 & 0.00413 & 446.00 & 522.00 & 522.00 & 522.00 & 0.89 & 1.08 & 0.96 \\
\hline PA2 & 0.00216 & 0.00468 & 432.00 & 522.00 & 522.00 & 522.00 & 0.89 & 1.10 & 0.98 \\
\hline PV4 & 0.00594 & 0.00100 & 242.00 & 242.00 & 242.00 & 242.00 & 0.88 & 1.00 & 0.88 \\
\hline PV6 & 0.00713 & 0.00113 & 266.00 & 266.00 & 266.00 & 266.00 & 1.04 & 1.00 & 1.04 \\
\hline PV9 & 0.00134 & 0.01017 & 268.45 & 213.85 & 210.13 & 210.13 & 1.14 & 0.88 & 1.00 \\
\hline PV10 & 0.00088 & 0.00327 & 176.64 & 276.00 & 248.07 & 276.00 & 0.74 & 1.19 & 0.88 \\
\hline PV11 & 0.00150 & 0.00510 & 235.00 & 235.00 & 235.00 & 235.00 & 1.01 & 1.00 & 1.01 \\
\hline PV12 & 0.00094 & 0.00075 & 187.60 & 269.00 & 280.64 & 269.00 & 0.64 & 1.22 & 0.78 \\
\hline PV16 & 0.00525 & 0.00428 & 255.00 & 255.00 & 255.00 & 255.00 & 0.88 & 1.00 & 0.88 \\
\hline PV19 & 0.00115 & 0.00860 & 229.00 & 299.00 & 330.41 & 299.00 & 0.75 & 1.20 & 0.90 \\
\hline PV20 & 0.00120 & 0.00533 & 239.20 & 297.00 & 348.83 & 297.00 & 0.79 & 1.21 & 0.95 \\
\hline PV21 & 0.00135 & 0.00137 & 270.22 & 302.00 & 347.45 & 302.00 & 0.86 & 1.13 & 0.98 \\
\hline PV22 & 0.00137 & 0.00092 & 274.80 & 382.20 & 342.60 & 378.81 & 0.88 & 1.11 & 0.98 \\
\hline PV23 & 0.00093 & -0.00008 & 186.48 & 227.92 & 212.39 & 212.39 & 0.81 & 1.01 & 0.82 \\
\hline PV24 & -0.00012 & 0.00042 & -24.60 & -14.76 & 141.85 & 141.85 & 0.79 & 1.46 & 1.15 \\
\hline PV25 & 0.00030 & 0.00270 & 60.58 & 79.22 & 89.86 & 89.86 & 0.83 & 1.05 & 0.87 \\
\hline PV26 & 0.00132 & 0.00123 & 264.48 & 463.00 & 368.09 & 463.00 & 0.87 & 1.18 & 1.02 \\
\hline PV27 & 0.00115 & 0.00188 & 229.84 & 234.26 & 355.82 & 355.82 & 0.65 & 1.53 & 1.00 \\
\hline PV28 & 0.00222 & 0.00435 & 444.36 & 410.55 & 416.97 & 416.97 & 0.99 & 0.97 & 0.96 \\
\hline PV29 & 0.00084 & 0.00154 & 167.58 & 324.00 & 293.96 & 324.00 & 0.85 & 1.20 & 1.02 \\
\hline
\end{tabular}




\begin{tabular}{|c|c|c|c|c|c|c|c|c|c|}
\hline PL1 & 0.00031 & 0.00891 & 62.00 & 529.00 & 265.38 & 529.00 & 0.71 & 1.16 & 0.82 \\
\hline PL2 & 0.00064 & 0.00688 & 128.00 & 529.00 & 474.89 & 529.00 & 0.71 & 1.43 & 1.01 \\
\hline PL3 & 0.00273 & 0.01100 & 546.00 & 529.00 & 604.00 & 529.00 & 0.77 & 1.08 & 0.84 \\
\hline PL4 & -0.00034 & 0.00258 & -68.00 & 516.00 & 149.64 & 529.00 & 0.71 & 1.15 & 0.81 \\
\hline PL5 & 0.00232 & 0.01410 & 464.00 & 529.00 & 600.55 & 529.00 & 0.84 & 1.14 & 0.95 \\
\hline PL6 & 0.00585 & 0.01070 & 604.00 & 529.00 & 604.00 & 529.00 & 0.60 & 1.00 & 0.60 \\
\hline & & & & \multicolumn{3}{|c|}{ Average } & 0.86 & 1.12 & 0.95 \\
\hline & & & & \multicolumn{3}{|c|}{ C.V. } & $16.39 \%$ & $14.45 \%$ & $11.47 \%$ \\
\hline & & & & \multicolumn{3}{|c|}{ Max } & 1.24 & 1.67 & 1.15 \\
\hline & & & & & \multicolumn{2}{|c|}{ Percentile (95\%) } & 1.07 & 1.45 & 1.12 \\
\hline & & & & & \multicolumn{2}{|c|}{ Percentile $(5 \%)$} & 0.64 & 0.96 & 0.79 \\
\hline & & & & & \multicolumn{2}{|l|}{ Min } & 0.56 & 0.86 & 0.60 \\
\hline
\end{tabular}

Table 4 


\begin{tabular}{|c|c|}
\hline $\begin{array}{l}\text { Kaufmann and Marti } \\
\text { (1998) [11] }\end{array}$ & $\begin{array}{l}\tau_{d} \leq\left[\left(\rho_{x} \cdot f_{y x}-\sigma_{x d}\right) \cdot\left(\rho_{y} \cdot f_{y y}-\sigma_{y d}\right)\right]^{0.5} \\
\tau_{d} \leq\left[\left(\rho_{x} \cdot f_{y x}-\sigma_{x d}\right) \cdot\left(\sqrt{2+\frac{25}{3} \cdot \frac{f_{c}^{2 / 3}}{\rho_{x} \cdot f_{y x}-\sigma_{x d}}}-\frac{29}{12}\right)\right]^{0.5} \\
\tau_{d} \leq\left[\left(\rho_{y} \cdot f_{y y}-\sigma_{y d}\right) \cdot\left(\sqrt{2+\frac{25}{3} \cdot \frac{f_{c}^{2 / 3}}{\rho_{y} \cdot f_{y y}-\sigma_{y d}}}-\frac{29}{12}\right)\right]^{0.5} \\
\tau_{d} \leq \frac{25}{29} \cdot f_{c}^{2 / 3}\end{array}$ \\
\hline $\begin{array}{l}\text { Carbone, Giordano and } \\
\text { Mancini (2001) [4] }\end{array}$ & $\begin{array}{l}\tau_{d} \geq-\left(\rho_{x} \cdot f_{y x}+\sigma_{x d}\right) \cdot \tan \theta_{p l} \\
\tau_{d} \leq\left(\rho_{x} \cdot f_{y x}-\sigma_{x d}\right) \cdot \tan \theta_{p l} \\
\tau_{d} \geq-\left(-\rho_{y} \cdot f_{y y}+\sigma_{y d}\right) \cdot \cot \theta_{p l} \\
\tau_{d} \leq\left(\rho_{y} \cdot f_{y y}-\sigma_{y d}\right) \cdot \cot \theta_{p l} \\
\tau_{d} \leq \sigma_{c} \cdot \sin \theta_{p l} \cdot \cos \theta_{p l} \\
\text { where: } \quad \sigma_{c} \text { maximum compression in the concrete stress field: } \\
\quad \text { if } \sigma_{\mathrm{sx}} \geq f_{y x} \text { or } \sigma_{\mathrm{sy}} \geq f_{y y}: \\
\quad \sigma_{c}=(1-0.032|\Delta \theta|) \cdot f_{c 2} \\
|\Delta \theta|=\left|\theta_{\mathrm{el}}-\theta_{\mathrm{pl}}\right|<15 \text { degrees } \\
\quad \theta_{\mathrm{el}} \text { inclination about the X axis of principal compressive } \\
\quad \text { stress in the elastic analysis (in degrees) } \\
\quad \theta_{\mathrm{pl}} \text { angle about the X axis of plastic compression field (in degrees) } \\
\quad \quad \quad \text { principal compressive stress) } \\
\text { in other case : } \\
\quad \sigma_{c}=\left[0.85 \cdot \frac{f_{c}}{f_{c 2}}-\frac{\sigma_{s}}{f_{y s}} \cdot\left(0.85 \cdot \frac{f_{c}}{f_{c 2}}-1\right)\right] \cdot f_{c 2} \\
f_{c 2}=0.6 \cdot\left(1-f_{c k} / 250\right) \cdot f_{c} \text { where } f_{c k}=f_{c}-8 \text { (in MPa) } \\
\sigma_{\mathrm{sx}}=\frac{\sigma_{x d}+\tau_{u} \cdot \cot \theta_{\mathrm{pl}}}{\rho_{x}} ; \sigma_{\mathrm{sy}}=\frac{\sigma_{y d}+\tau_{u} \cdot \text { tan } \theta_{\mathrm{pl}}}{\rho_{y}} \\
\sigma_{s} \text { maximum tensile stress value in the reinforcement whose } \\
\text { yield strength is } f_{y s} \\
\text { ultimate shear stress }\end{array}$ \\
\hline Rahal (2008) [16] & $\begin{array}{l}\tau_{d} \leq f_{c} \cdot\left(\omega_{x} \cdot \omega_{y}\right)^{0.5} \leq f_{c} \cdot \kappa \\
\text { where : } \\
\omega_{\mathrm{x}}=\frac{\rho_{x} \cdot f_{y x}-\sigma_{x d}}{f_{c}} \leq \kappa \\
\omega_{\mathrm{y}}=\frac{\rho_{y} \cdot f_{y y}-\sigma_{y d}}{f_{c}} \leq \kappa \\
\kappa=1 / 3-f_{c} / 900\end{array}$ \\
\hline
\end{tabular}

Table 5 

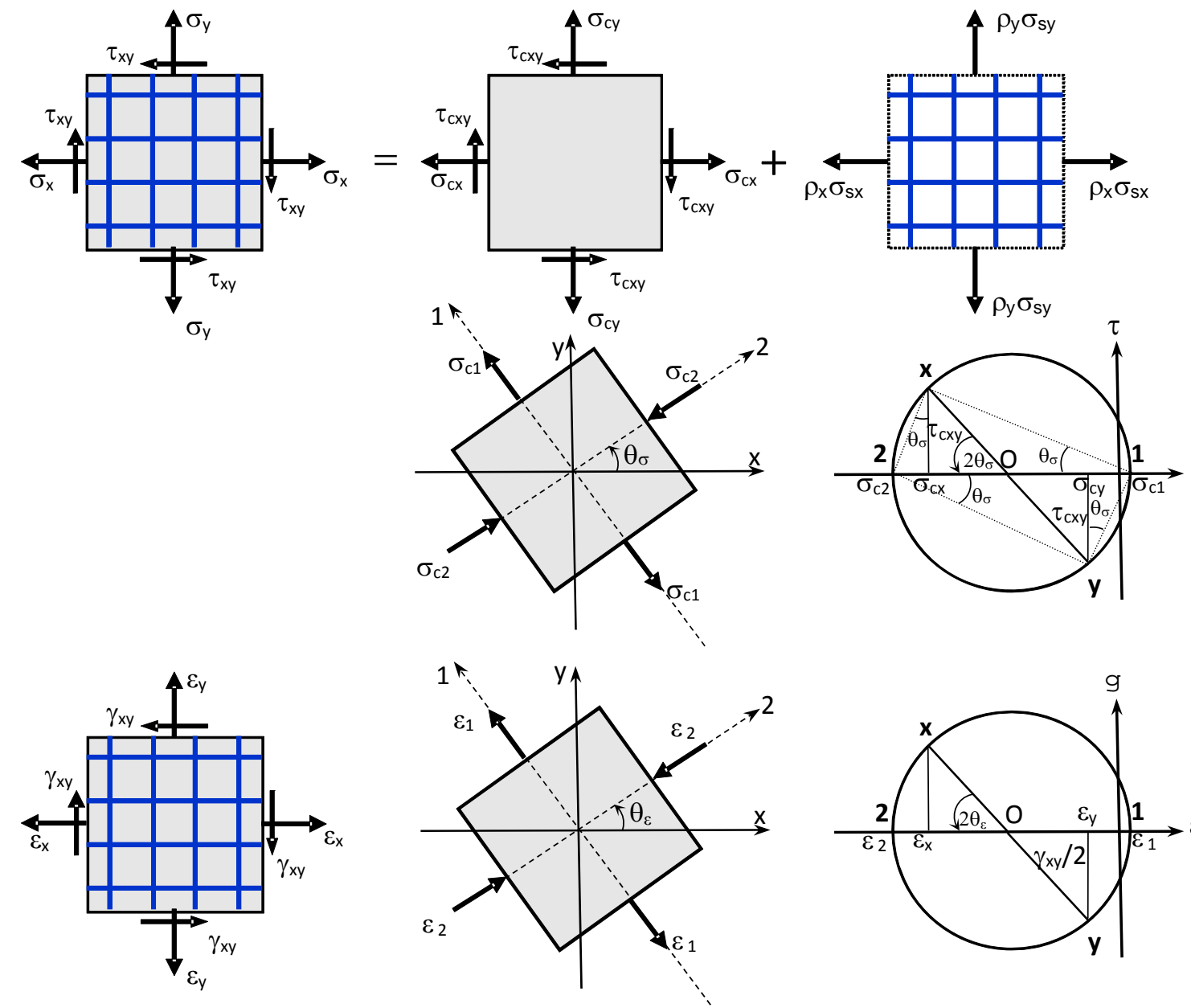

Figure 1 


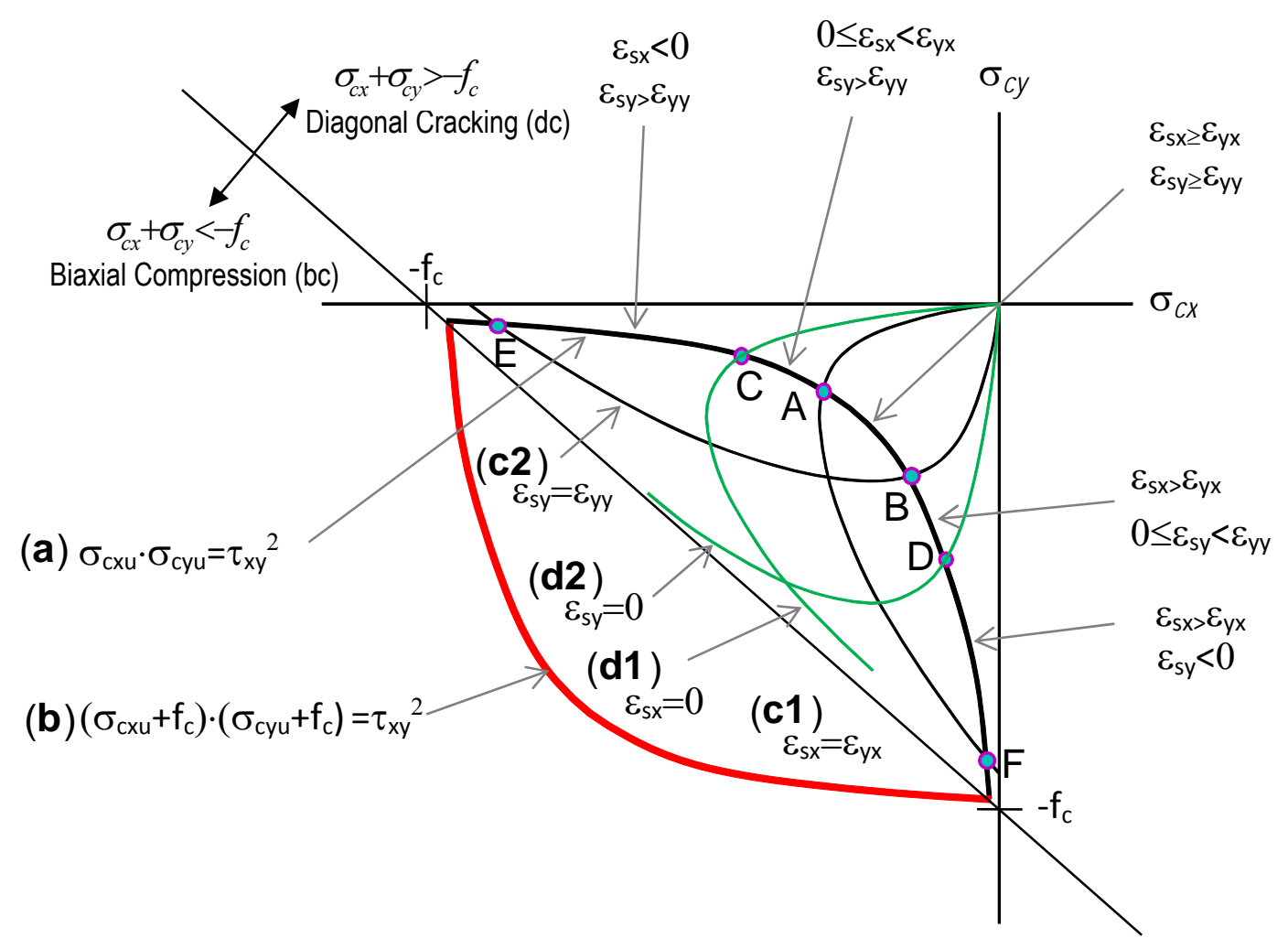

Figure 2 


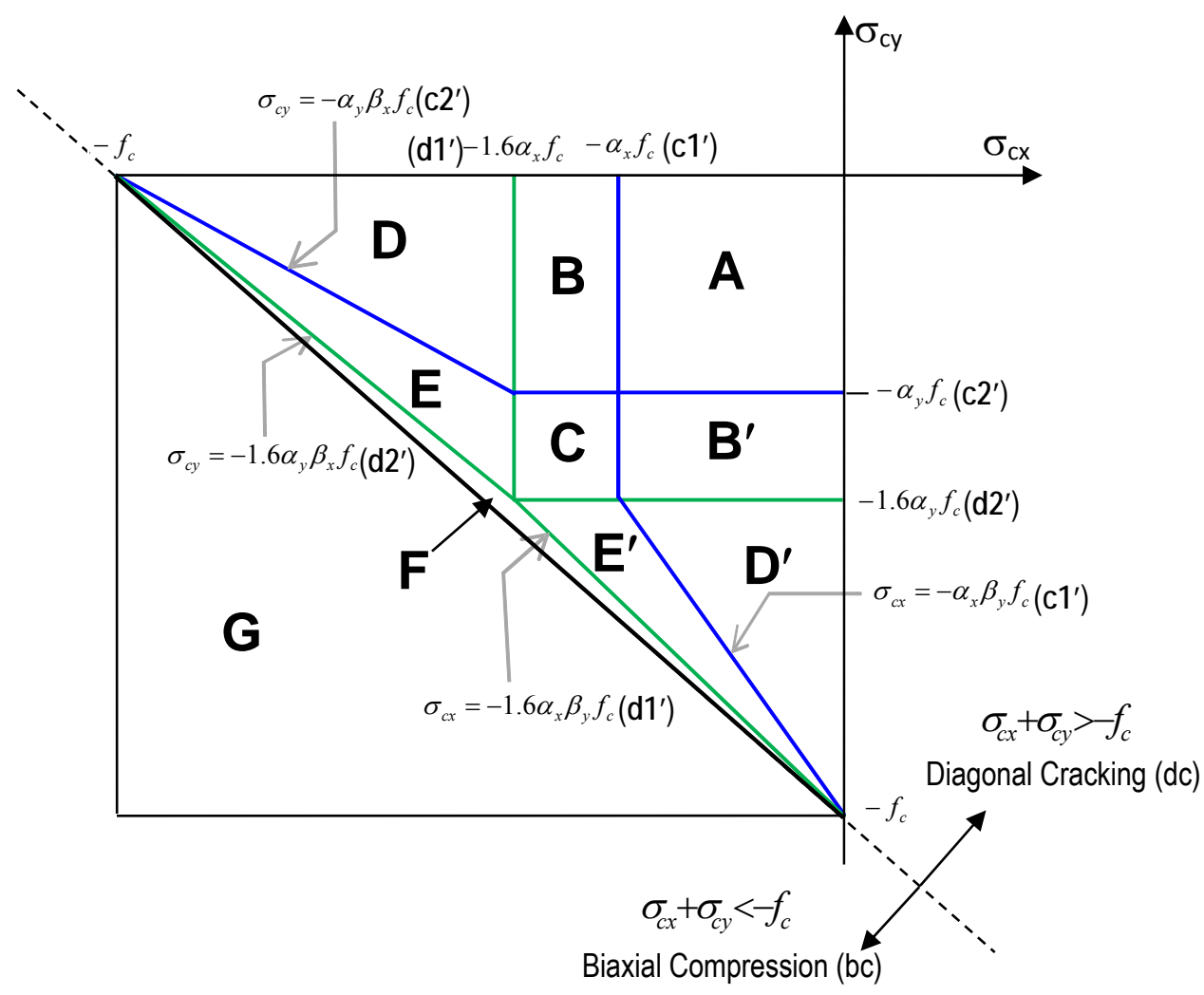

Figure 3 


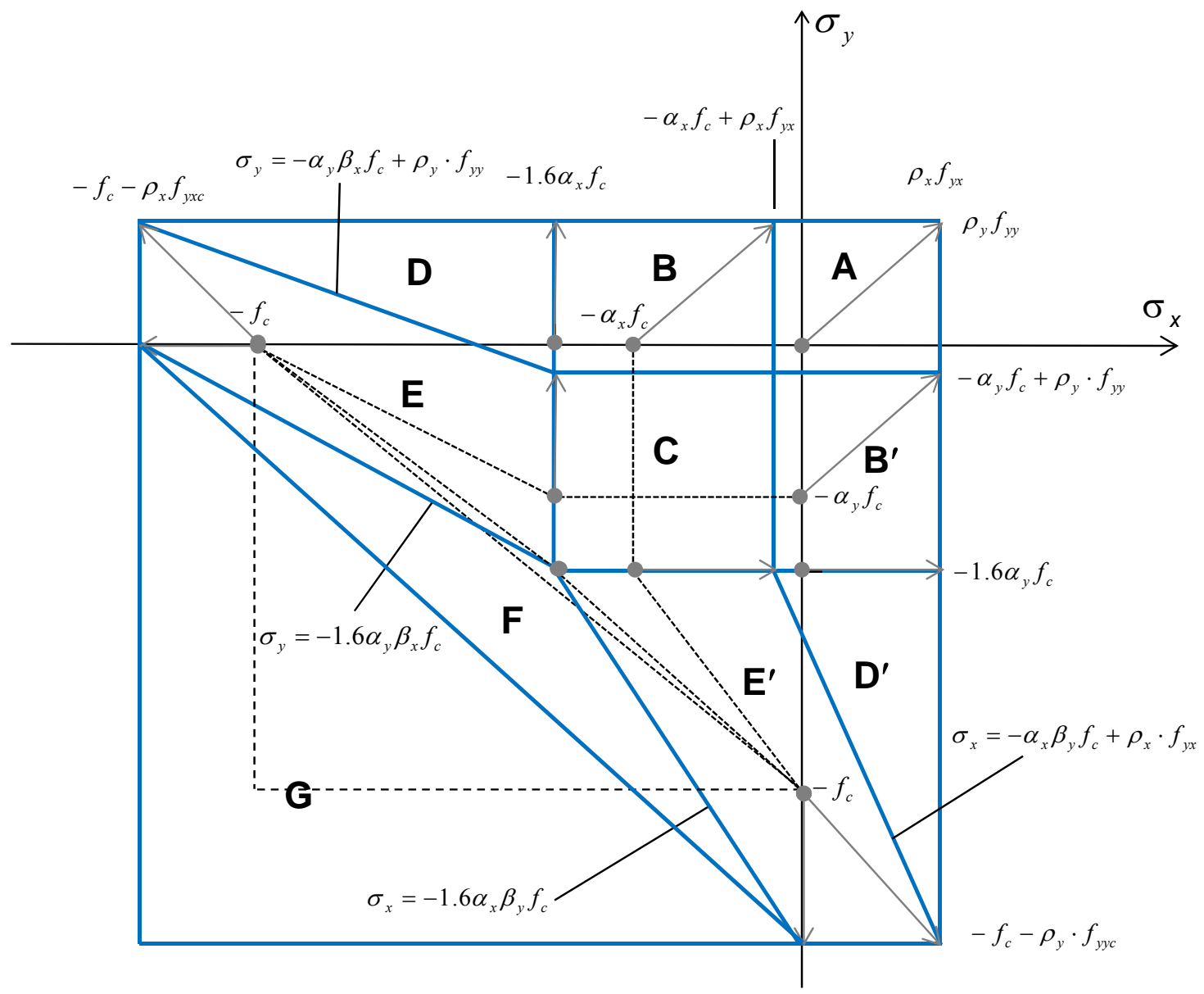

Figure 4 


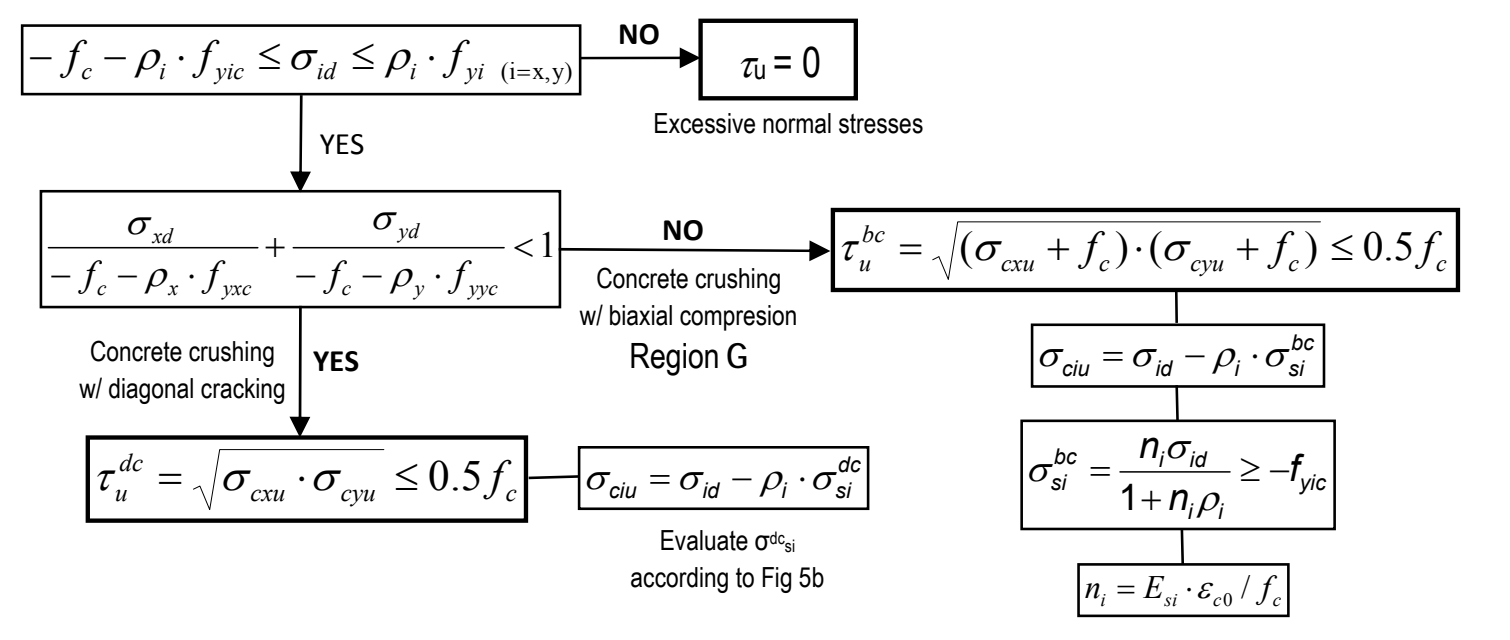

Fig 5b: Evaluation of steel stresses in case of concrete crushing w/ diagonal cracking, and mode of failure

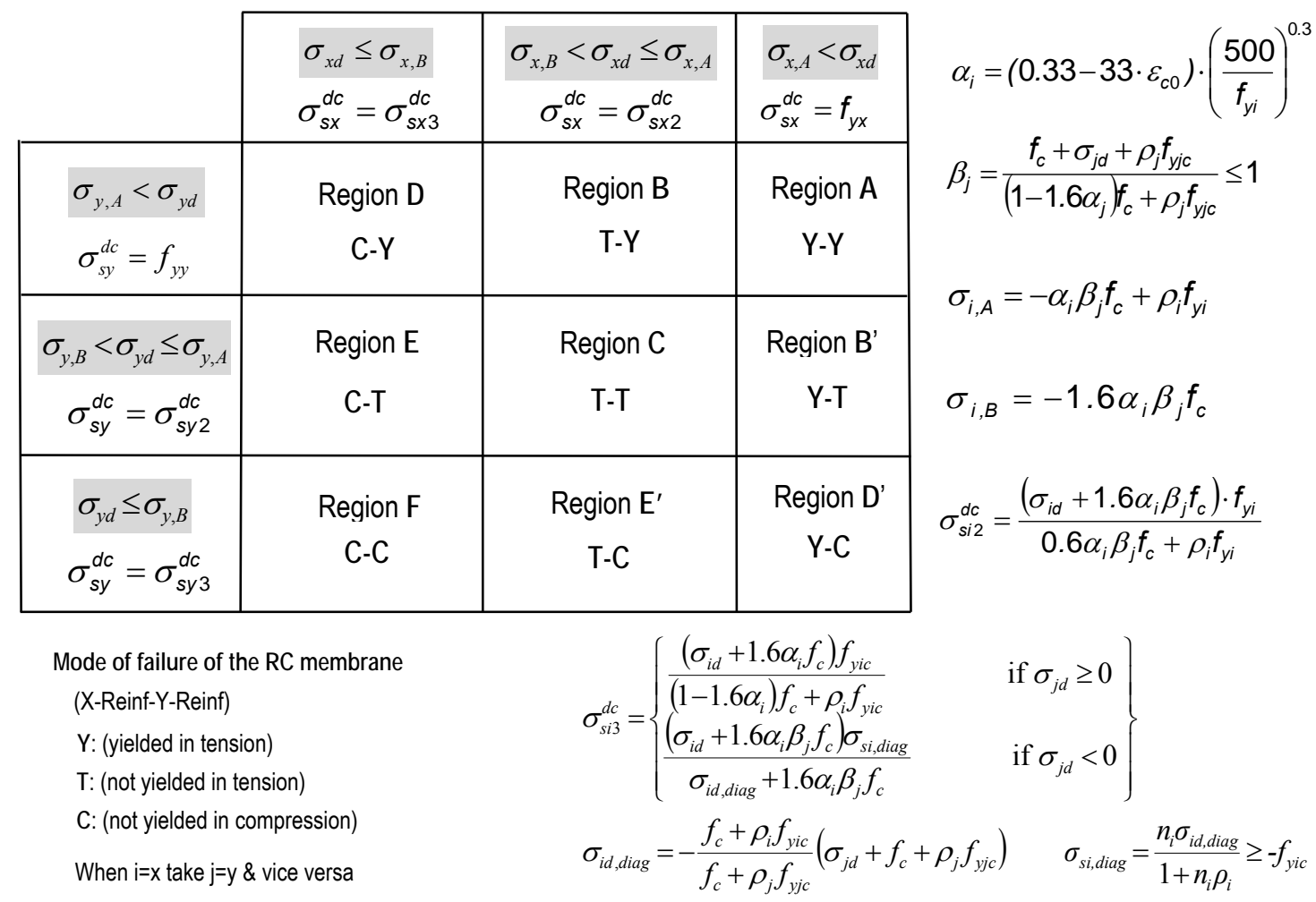

Figure 5 


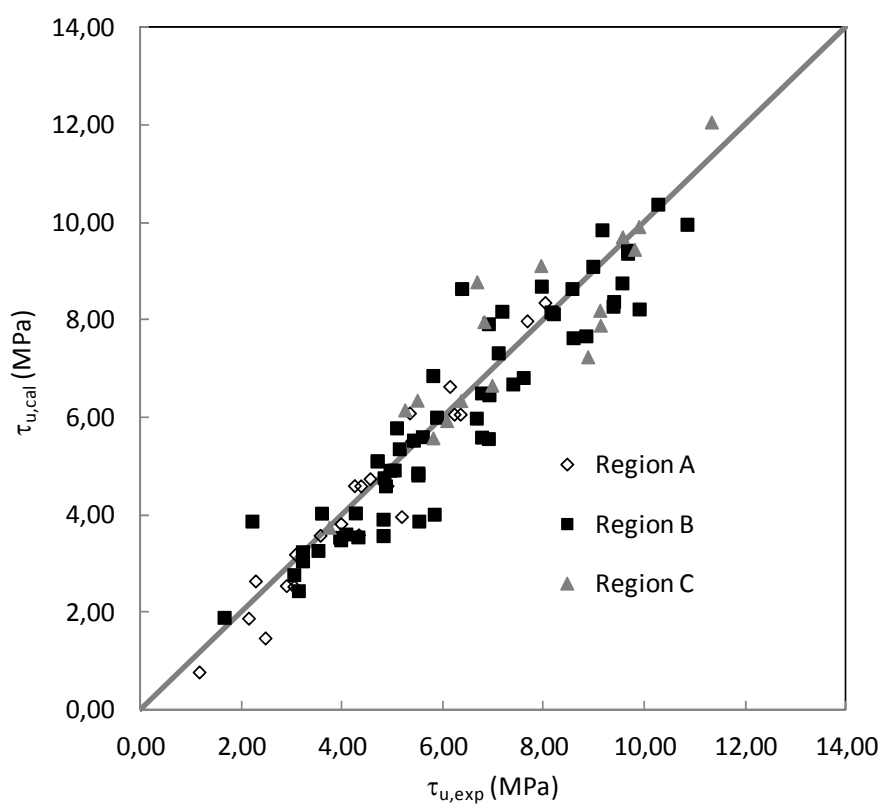

Figure 6 
(a)

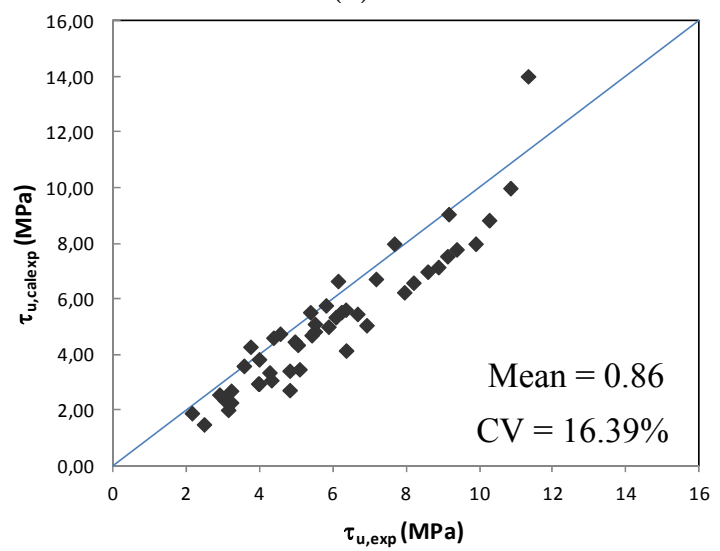

(b)

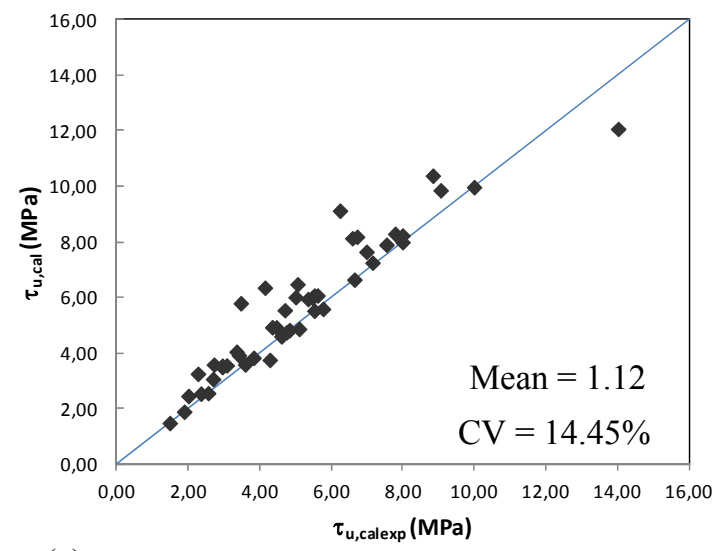

(c)

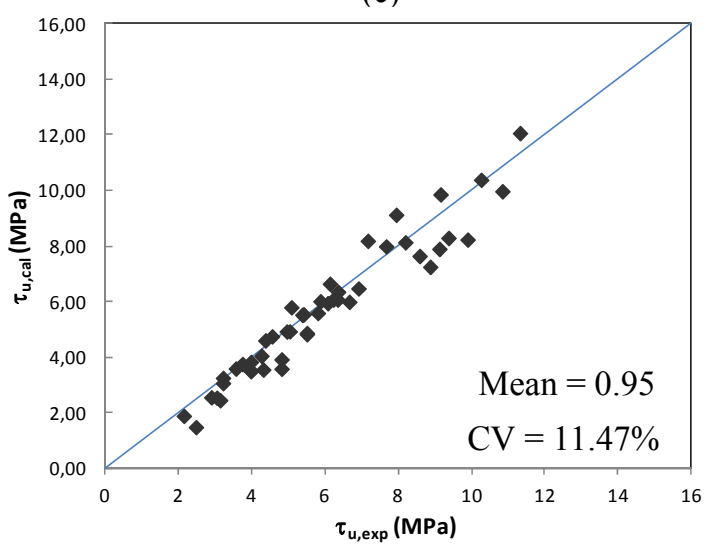

Figure 7 


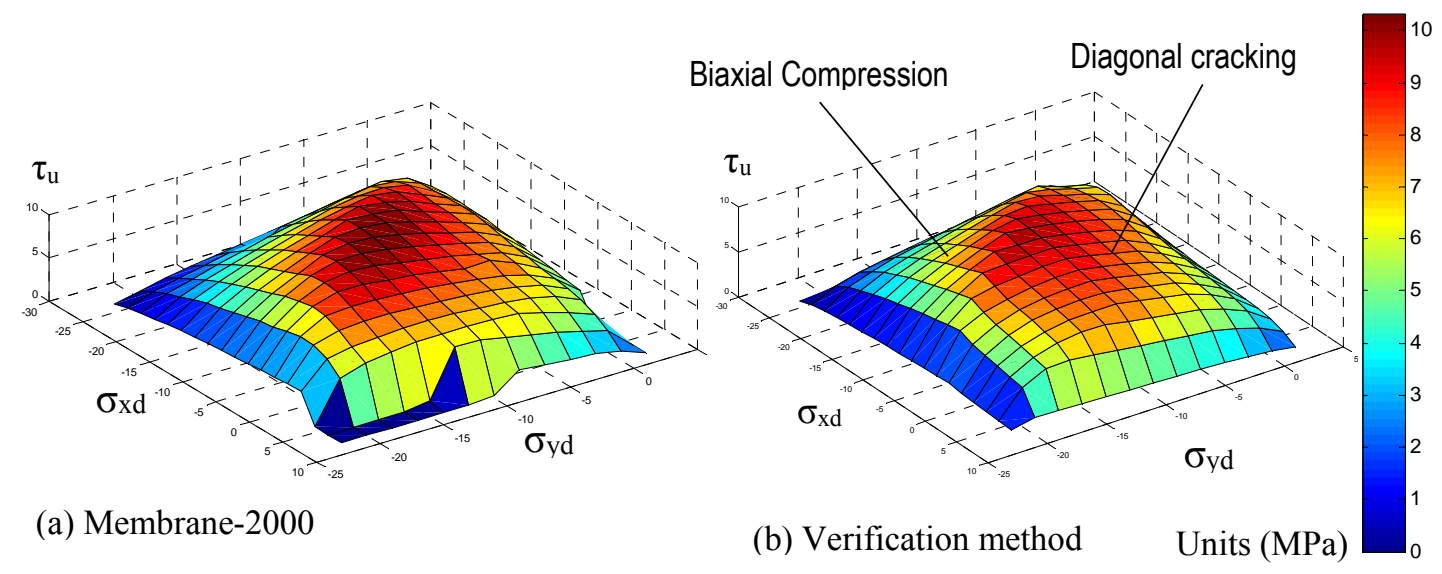

Figure 8 


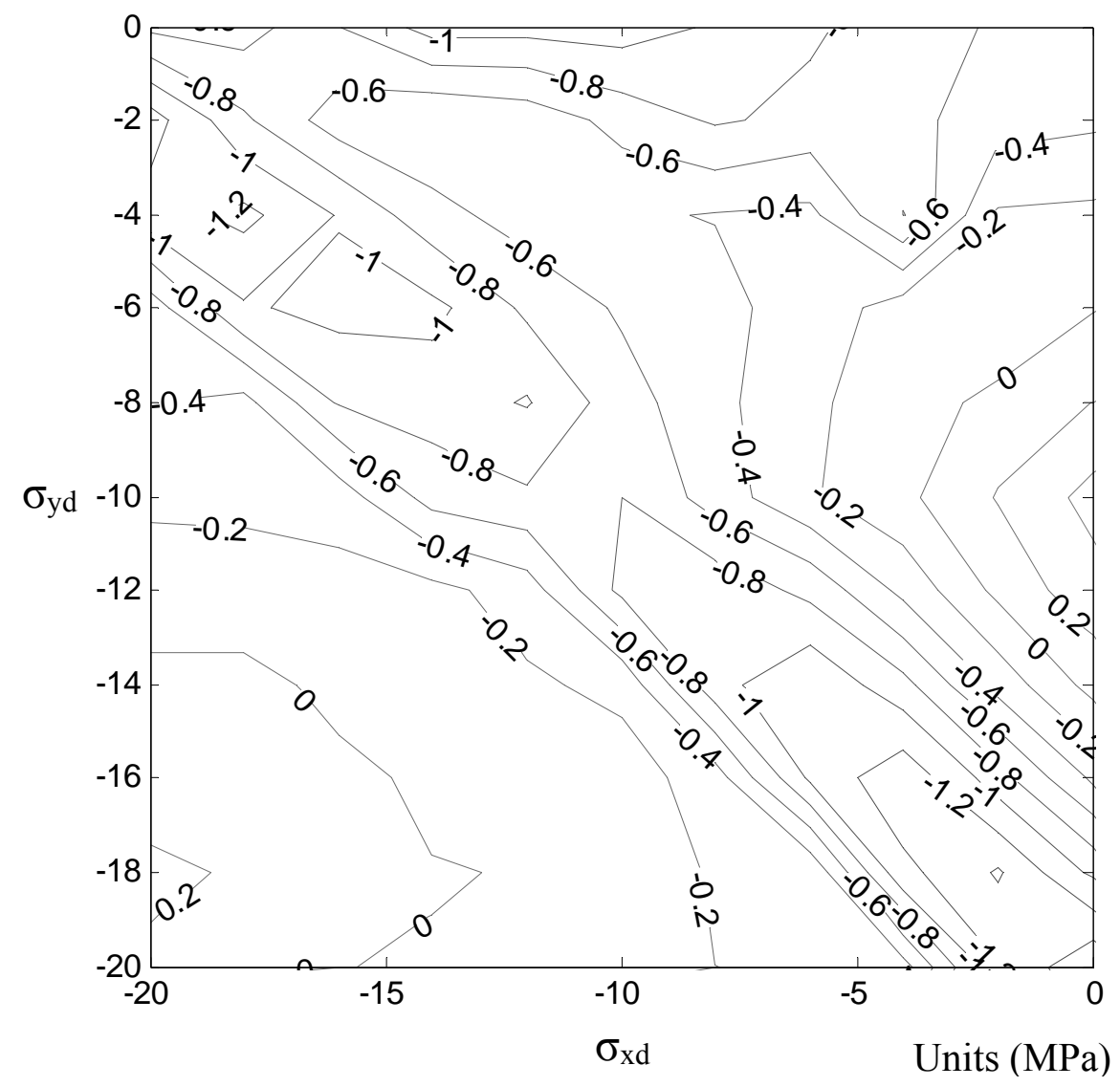

Figure 9 
Annex 1 Data and results predicted by the proposed model for 88 experimental tests

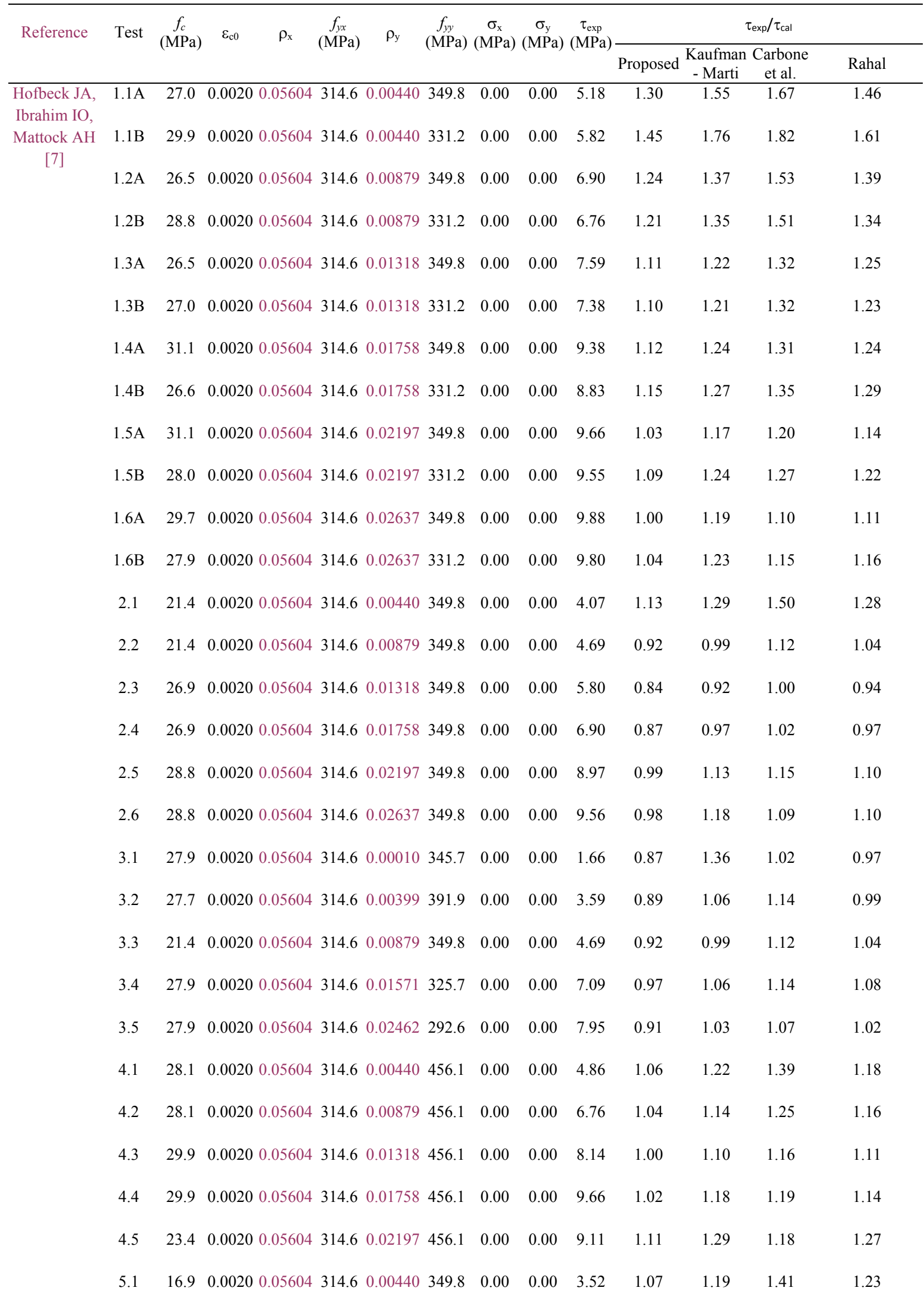




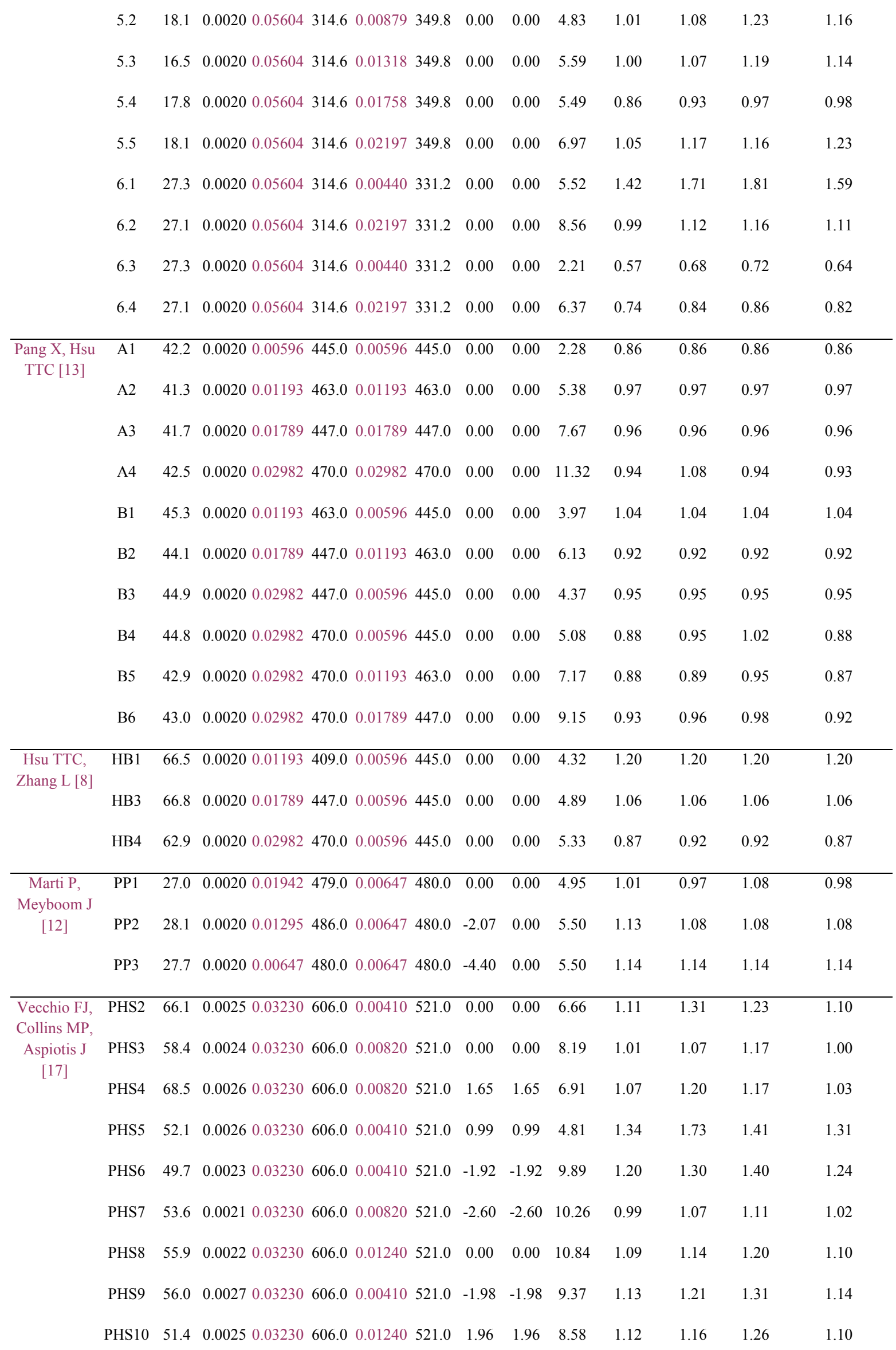




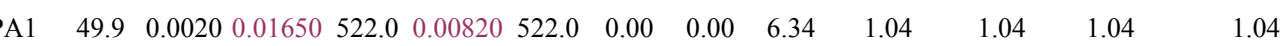

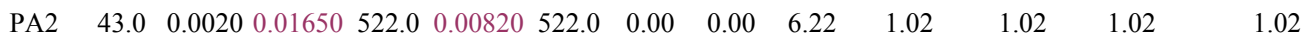

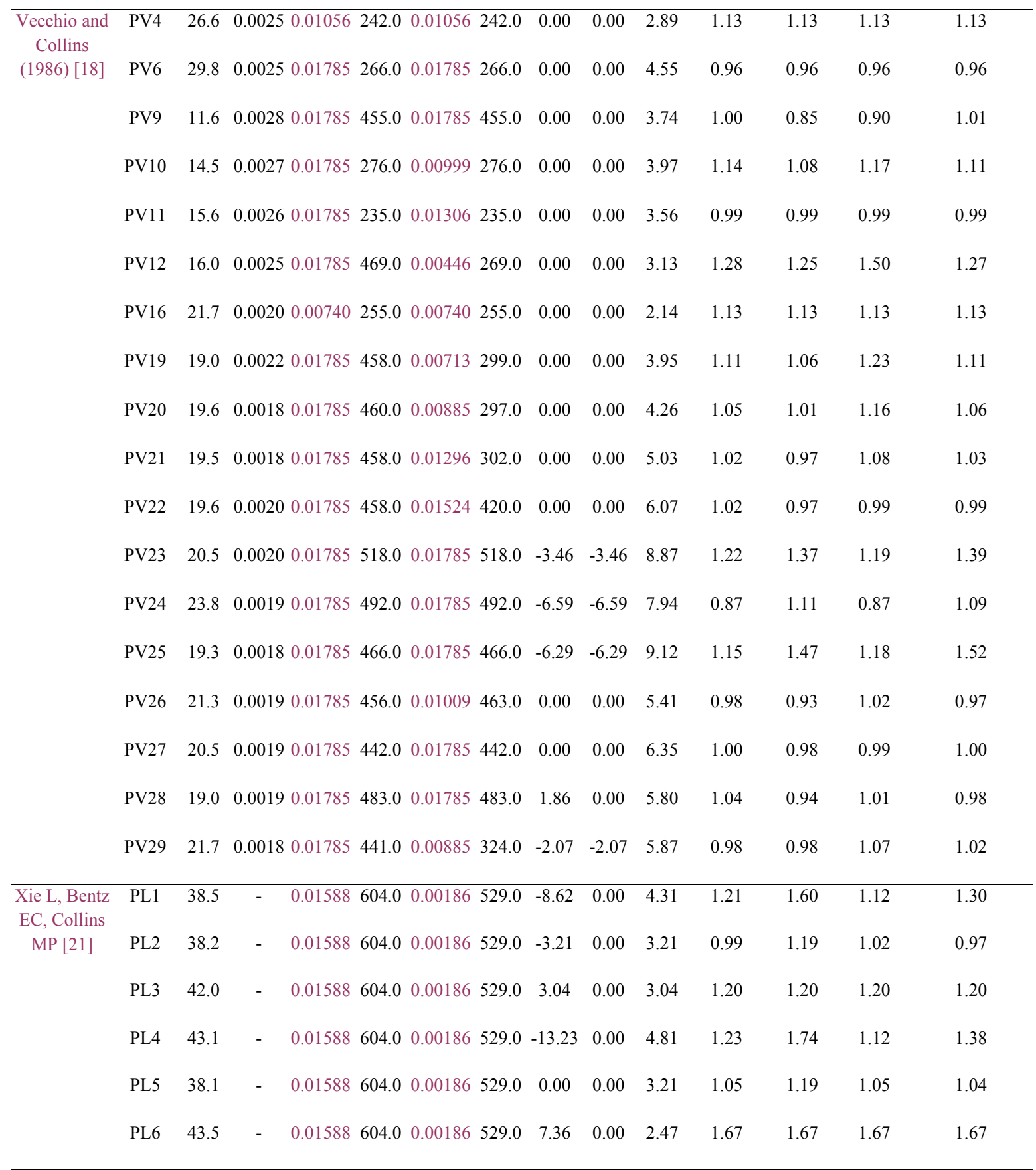




\section{Annex 2. Verification examples}

Materials: $f_{c}=19.25 \mathrm{MPa} ; \varepsilon_{c 0}=0.0018 ; \rho_{x}=\rho_{y}=0.01785 ; f_{y x}=f_{y y}=466 \mathrm{MPa}$

Stresses at failure: $\sigma_{x d}=\sigma_{y d}=-6.29 \mathrm{MPa} ; \tau_{u, \exp }=9.12 \mathrm{MPa}$

Step 1: verify $-f_{c}-\rho_{x} \cdot f_{y x c} \leq \sigma_{x d} \leq \rho_{x} \cdot f_{y x} \rightarrow-19.25-0.01785 \cdot 360 \leq-6.29 \leq 0.01785 \cdot 466 \rightarrow$ Yes $-f_{c}-\rho_{y} \cdot f_{y y c} \leq \sigma_{y d} \leq \rho_{y} \cdot f_{y y} \quad-25.67 \leq-6.29 \leq 8.32$

Step 2: $\frac{\sigma_{x d}}{-f_{c}-\rho_{x} \cdot f_{y x c}}+\frac{\sigma_{y d}}{-f_{c}-\rho_{y} \cdot f_{y y c}}<1 \rightarrow 2 \cdot \frac{-6.29}{-25.67}=0.49<1 \rightarrow$ Yes, diagonal cracking

Step 3: Type of region and steel stresses

$$
\begin{aligned}
& \alpha_{x}=\alpha_{y}=(0.33-33 \cdot 0.018) \cdot\left(\frac{500}{466}\right)^{0.3}=0.276 \\
& \beta_{x}=\beta_{y}=\frac{19.25-6.29+0.01785 \cdot 360}{(1-1.6 \cdot 0.276) \cdot 19.25+0.01785 \cdot 360}=1.13 \leq 1 \\
& \sigma_{x d}=-6.29 \leq \sigma_{x, A}=-\alpha_{x} \cdot \beta_{y} \cdot f_{c}+\rho_{x} \cdot f_{y x}=3.00 \& \sigma_{x, B}=-1.6 \cdot \alpha_{x} \cdot f_{c}=-8.51<\sigma_{x d}=-6.29 \\
& \sigma_{y d}=-6.29 \leq \sigma_{y, A}=-\alpha_{y} \cdot \beta_{x} \cdot f_{c}+\rho_{y} \cdot f_{y y}=3.00 \& \sigma_{y, B}=-1.6 \cdot \alpha_{y} \cdot f_{c}=-8.51<\sigma_{y d}=-6.29
\end{aligned}
$$

Hence, the membrane region is $\mathrm{C}$ and the mode of failure is (T-T)

$$
\begin{aligned}
& \sigma_{s x}^{d c}=\frac{\left(\sigma_{x d}+1.6 \cdot \alpha_{x} \cdot \beta_{y} \cdot f_{c}\right) \cdot f_{y x}}{0.6 \cdot \alpha_{x} \cdot \beta_{y} \cdot f_{c}+\rho_{x} \cdot f_{y x}}=\frac{(-6.29+1.6 \cdot 1 \cdot 0.276 \cdot 19.25) \cdot 466}{0.6 \cdot 0.277 \cdot 1 \cdot 19.25+0.01785 \cdot 466}=89.86 \mathrm{MPa} \\
& \sigma_{s y}^{d c}=\frac{\left(\sigma_{y d}+1.6 \cdot \alpha_{y} \cdot \beta_{x} \cdot f_{c}\right) \cdot f_{y y}}{0.6 \cdot \alpha_{y} \cdot \beta_{x} \cdot f_{c}+\rho_{y} \cdot f_{y y}}=89.86 \mathrm{MPa}
\end{aligned}
$$

Step 4: Concrete stresses at failure

$$
\begin{aligned}
& \sigma_{c x u}=\sigma_{x d}-\rho_{x} \sigma_{s x}^{d c}=-6.29-0.01785 \cdot 89.86=-7.90 \mathrm{MPa} \\
& \sigma_{c y u}=\sigma_{y d}-\rho_{y} \sigma_{s y}^{d c}=-7.90 \mathrm{MPa}
\end{aligned}
$$

Step 5: Ultimate shear stress of the panel

$$
\begin{aligned}
& \tau_{u}^{d c}=\sqrt{\sigma_{c x u} \cdot \sigma_{c y u}}=\sqrt{(-7.90) \cdot(-7.90)}=7.90 \mathrm{MPa} \\
& \tau_{u, \text { exp }} / \tau_{u}^{d c}=1.15
\end{aligned}
$$

2.1 Example 2: Specimen PL1 by Xie L, Bentz EC, Collins MP [21]

Materials: $f_{c}=38.5 \mathrm{MPa} ; \varepsilon_{c 0}=0.002$ (estimated); $\rho_{x}=0.01588 ; \rho_{y}=0.00186 ; f_{y x}=604 \mathrm{MPa} ; f_{y y}=529 \mathrm{MPa}$

Stresses at failure: $\sigma_{x d}=-8.62 \mathrm{MPa} ; \sigma_{y d}=0 \mathrm{MPa} ; \tau_{u, \exp }=4.31 \mathrm{MPa}$ 
Step 1: verify $-f_{c}-\rho_{x} \cdot f_{y x c} \leq \sigma_{x d} \leq \rho_{x} \cdot f_{y x} \rightarrow-38.5-0.01588 \cdot 400=-44.85 \leq-8.62 \leq 0.01588 \cdot 604=9.59 \rightarrow$ Yes $-f_{c}-\rho_{y} \cdot f_{y y c} \leq \sigma_{y d} \leq \rho_{y} \cdot f_{y y} \quad-38.5-0.00186 \cdot 400=-39.24 \leq 0 \leq 0.00186 \cdot 529=0.98$

Step 2: $\frac{\sigma_{x d}}{-f_{c}-\rho_{x} \cdot f_{y x c}}+\frac{\sigma_{y d}}{-f_{c}-\rho_{y} \cdot f_{y y c}}<1 \rightarrow \frac{-8.62}{-44.85}+\frac{0}{-39.24}=0.19<1 \rightarrow$ Yes, diagonal cracking

Step 3: Type of region and steel stresses

$$
\begin{aligned}
& \alpha_{x}=(0.33-33 \cdot 0.01588) \cdot\left(\frac{500}{604}\right)^{0.3}=0.2495 \\
& \alpha_{y}=(0.33-33 \cdot 0.00186) \cdot\left(\frac{500}{529}\right)^{0.3}=0.2596 \\
& \beta_{x}=\frac{38.5-8.62+0.01588 \cdot 400}{(1-1.6 \cdot 0.2495) \cdot 38.5+0.01588 \cdot 400}=1.23 \leq 1 \rightarrow \beta_{x}=1 \\
& \beta_{y}=\frac{38.5+0+0.00186 \cdot 400}{(1-1.6 \cdot 0.2596) \cdot 38.5+0.00186 \cdot 400}=1.69 \leq 1 \rightarrow \beta_{y}=1 \\
& \sigma_{x d}=-8.62 \leq \sigma_{x, A}=-\alpha_{x} \cdot \beta_{y} \cdot f_{c}+\rho_{x} \cdot f_{y x}=-0.0123 \& \sigma_{x, B}=-1.6 \cdot \alpha_{x} \cdot \beta_{y} \cdot f_{c}=-15.37<\sigma_{x d}=-8.62 \\
& \sigma_{y d}=0>\sigma_{y, A}=-\alpha_{y} \cdot \beta_{x} \cdot f_{c}+\rho_{y} \cdot f_{y y}=-9.01
\end{aligned}
$$

Hence, the membrane region is $\mathrm{B}$ and the mode of failure is (T-Y)

$$
\begin{aligned}
& \sigma_{s x}^{d c}=\frac{\left(\sigma_{x d}+1.6 \cdot \alpha_{x} \cdot \beta_{y} \cdot f_{c}\right) \cdot f_{y x}}{0.6 \cdot \alpha_{x} \cdot \beta_{y} \cdot f_{c}+\rho_{x} \cdot f_{y x}}=\frac{(-8.62+1.6 \cdot 0.2495 \cdot 1 \cdot 38.5) \cdot 604}{0.6 \cdot 0.2495 \cdot 1 \cdot 38.5+0.01588 \cdot 604}=265.38 \mathrm{MPa} \\
& \sigma_{s y}^{d c}=f_{y y}=529 \mathrm{MPa}
\end{aligned}
$$

Step 4: Concrete stresses at failure

$$
\begin{aligned}
& \sigma_{c x u}=\sigma_{x d}-\rho_{x} \sigma_{s x}^{d c}=-8.62-0.01588 \cdot 265.38=-12.83 \mathrm{MPa} \\
& \sigma_{c y u}=\sigma_{y d}-\rho_{y} \sigma_{s y}^{d c}=0-0.00186 .529=-0.98 \mathrm{MPa}
\end{aligned}
$$

Step 5: Ultimate shear stress of the panel

$$
\begin{aligned}
& \tau_{u}^{d c}=\sqrt{\sigma_{c x u} \cdot \sigma_{c y u}}=\sqrt{(-12.83) \cdot(-0.98)}=3.55 \mathrm{MPa} \\
& \tau_{u, \exp } / \tau_{u}^{d c}=1.21
\end{aligned}
$$

